San Jose State University

SJSU ScholarWorks

Dissertations

Master's Theses and Graduate Research

Summer 2018

\title{
Teacher and Administrator Knowledge, Beliefs, Attitudes, and Practices Related to Equity in a Suburban California School District
}

Arcia Dorosti

San Jose State University

Follow this and additional works at: https://scholarworks.sjsu.edu/etd_dissertations

\section{Recommended Citation}

Dorosti, Arcia, "Teacher and Administrator Knowledge, Beliefs, Attitudes, and Practices Related to Equity in a Suburban California School District" (2018). Dissertations. 23.

DOI: https://doi.org/10.31979/etd.zn8d-xypy

https://scholarworks.sjsu.edu/etd_dissertations/23

This Dissertation is brought to you for free and open access by the Master's Theses and Graduate Research at SJSU ScholarWorks. It has been accepted for inclusion in Dissertations by an authorized administrator of SJSU ScholarWorks. For more information, please contact scholarworks@sjsu.edu. 


\title{
TEACHER AND ADMINISTRATOR KNOWLEDGE, BELIEFS, ATTITUTDES, AND PRACTICES RELATED TO EQUITY IN A SUBURBAN CALIFORNIA SCHOOL DISTRICT
}

\author{
A Dissertation \\ Presented to \\ The Faculty of the Educational Doctoral Program in Educational Leadership \\ San José State University \\ In Partial Fulfillment \\ of the Requirements for the Degree \\ Doctor of Education
}

by

Arcia Dorosti

August 2018 
(C)2018

Arcia Dorosti

ALL RIGHTS RESERVED 
The Designated Dissertation Committee Approves the Dissertation Titled

TEACHER AND ADMINISTRATOR KNOWLEDGE, BELIEFS, ATTITUTDES, AND PRACTICES RELATED TO EQUITY IN A SUBURBAN CALIFORNIA SCHOOL DISTRICT

by

Arcia Dorosti

APPROVED FOR THE EDUCATIONAL DOCTORAL PROGRAM IN EDUCATIONAL LEADERSHIP

SAN JOSÉ STATE UNIVERSITY

August 2018

Arnold Danzig, Ph.D.

Kathleen McConnell, Ph.D.

Diana Abbati, Ed.D.
Ed.D. Leadership Program

Department of Communication Studies

School Administrator 


\title{
ABSTRACT \\ TEACHER AND ADMINISTRATOR KNOWLEDGE, BELIEFS, ATTITUTDES, AND PRACTICES RELATED TO EQUITY IN A SUBURBAN CALIFORNIA SCHOOL DISTRICT
}

\author{
by Arcia Dorosti
}

This dissertation is a case study of one district's efforts to reduce the disparities in educational outcomes among its ethnic groups as well as the disparities in educational outcomes between its economically disadvantaged students and its students that are not economically disadvantaged. The literature reviewed began with the larger historical context around equity issues in education and then discussed in-school and out-of-school factors affecting educational outcomes. The methods used included interviews with teachers and administrators, site visits, and classroom observations. The results summarized the successes and remaining challenges facing the district as it continues its desired journey towards more equitable educational outcomes for the students they serve. 


\section{ACKNOWLEDGMENTS}

The completion of this dissertation is the byproduct of the patience and understanding of many individuals. The first person that I would like to recognize is my loving wife, who didn't particularly agree with my decision to go back to school but somehow supported me and stuck with me through the entire process. There were dark times in which I did not know if our relationship would survive, and through it all she carried our young family on her back while I was spread thin between work, classes, and my selfish adventures to preserve my sanity. I know that I wasn't necessarily the best husband and father through it all, but we survived with our family intact because of your strength and ability to endure. Velina, I am nothing without you and I owe you everything. I love you.

The second person that I would like to recognize is my advisor, Dr. Arnie Danzig, first and foremost for designing and leading an outstanding program in which I learned and grew a tremendous amount, but more importantly for his support and guidance through the dissertation process. He knew when and how to push me and when to baby me and give me slack. He was masterful in the way that he handled me through my emotional rollercoasters. Arnie, I know I am not always easy to work with, but I will forever be grateful for your vision and leadership. I feel very lucky for having met you and for getting to work with you. Thank you. I would also like to thank Dr. Abbati and Dr. McConnell for their thoughtful guidance throughout the dissertation process and for agreeing to serve on my committee. 
I would be a real jerk if I did not take the time to recognize Mel (and Paul) for being my thought partners, my intellectual sparring mates, and my motivators when I wanted to give up. Mel, you promised that you would drag me across the finish line and you did. I appreciate all of our conversations, study sessions, all of the meals you made me, and the workouts you forced me to participate in. You knew that we would need to be mentally and physically strong and that we would have to maintain our health as best as possible to complete this journey, and you were right all along. I am in this position because of you. Being around you has made me a better person. Thank you.

Finally, I would like to acknowledge my mother and father. You told me from the day I was born that education is important and that it would be a shame if I did not reach my potential. You told me that you would do anything to support me in any way, to help me reach my educational goals, and when it came down to it you delivered. You delivered emotionally and monetarily, like you always have. I know that I haven't always been the best student and the easiest kid to raise, and that I have given you a hard time and probably worried you to death night after night, but I hope I have accomplished something that will make you proud. I love you both. Thank you. 


\section{TABLE OF CONTENTS}

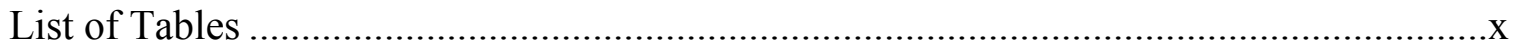

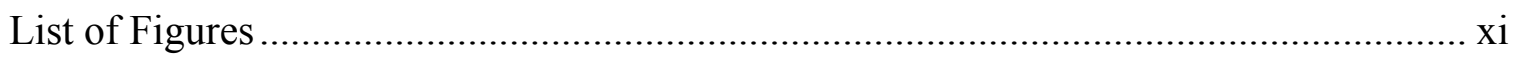

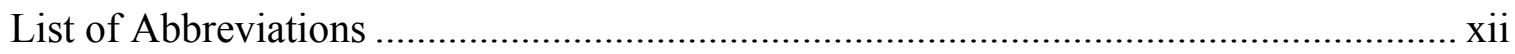

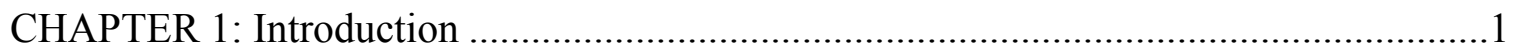

Background Information on the Study ............................................................ 3

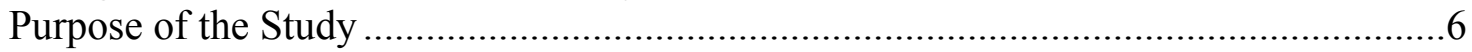

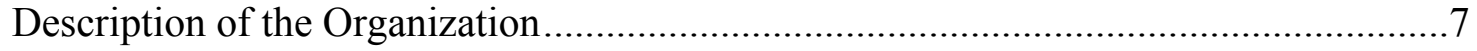

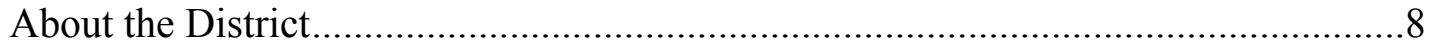

District setting and historical perspective .......................................................... 8

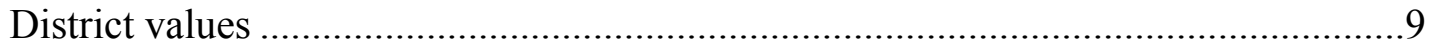

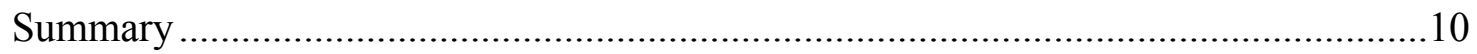

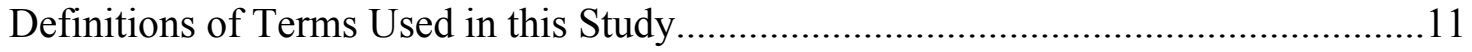

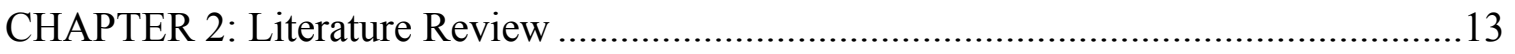

Historical Context ........................................................................................... 14

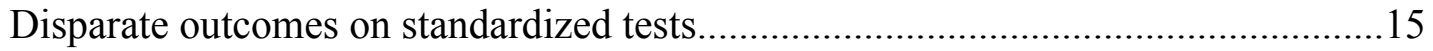

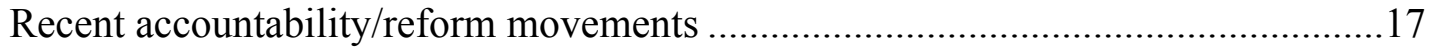

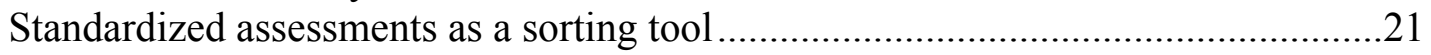

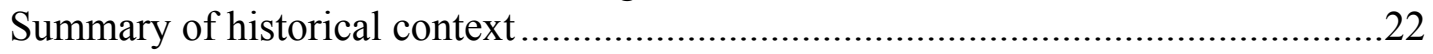

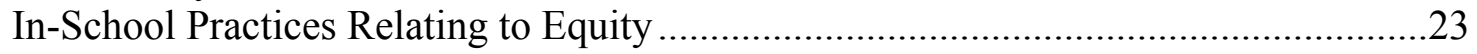

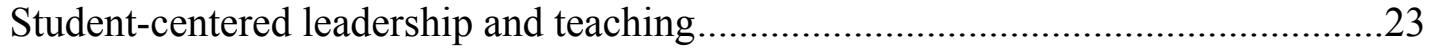

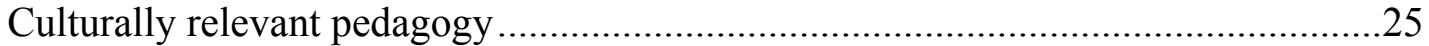

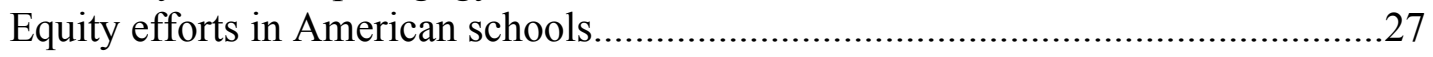

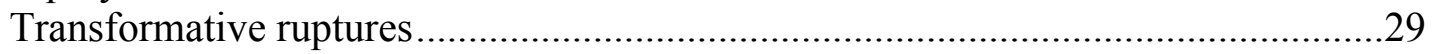

Empirical Data on Factors Affecting Educational Outcomes...................................29

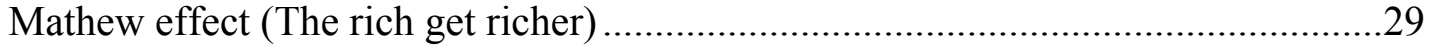

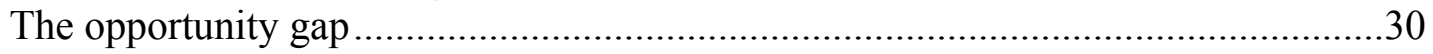

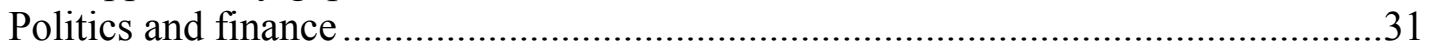

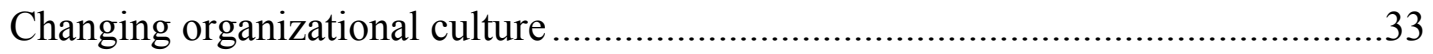

Conceptual Research on Factors Affecting Educational Outcomes ............................34

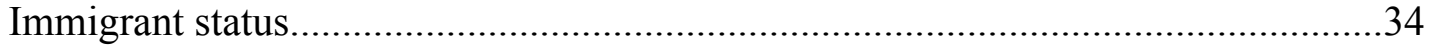

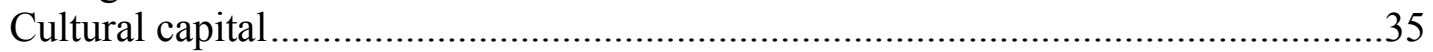

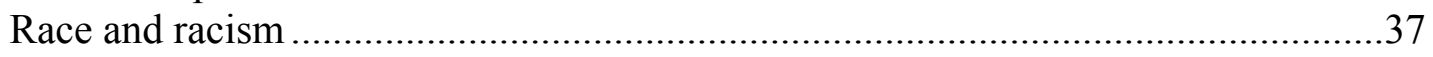

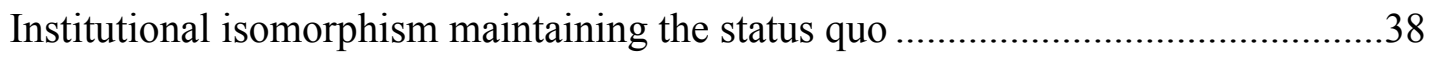

Summary of factors affecting educational outcomes............................................ 41 


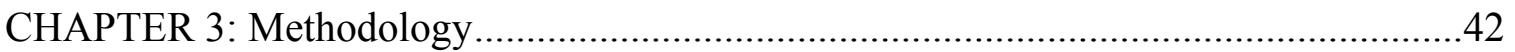

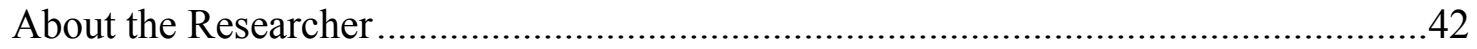

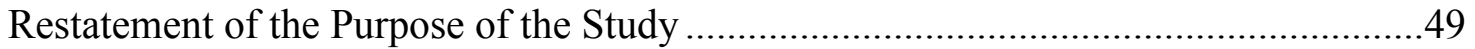

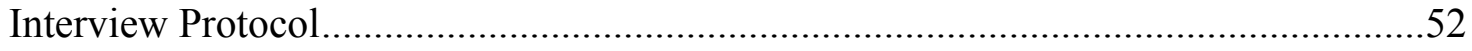

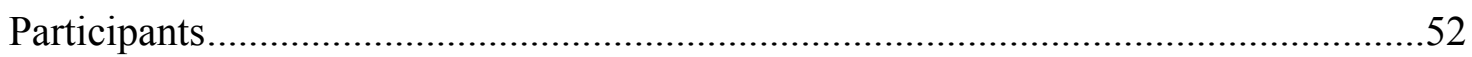

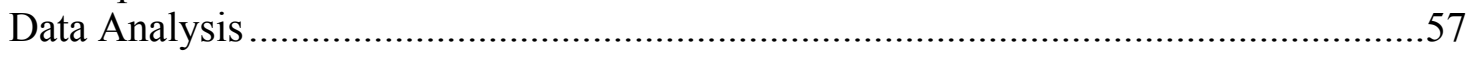

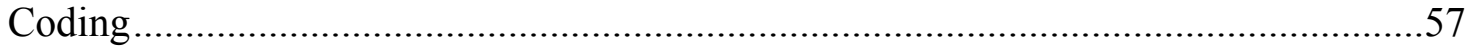

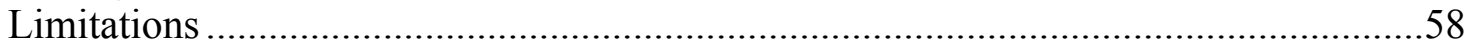

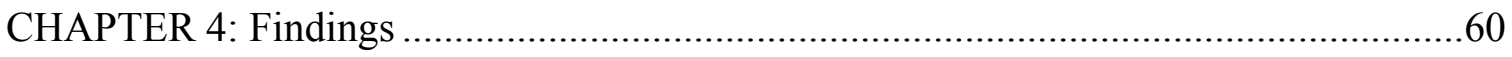

Ocotillo SBAC Results 2015-17 and Research Question \#1 .......................................61

Ocotillo School District enrollment in Advanced Placement courses ........................62

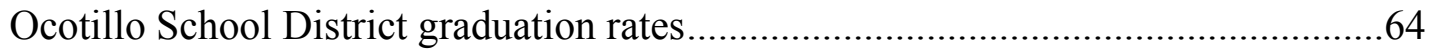

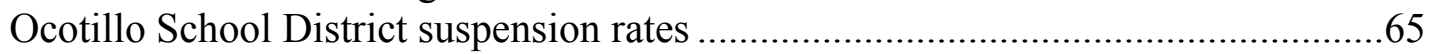

Ocotillo School District chronic absenteeism...........................................................66

Progress towards implementation of MATD recommendations .................................67

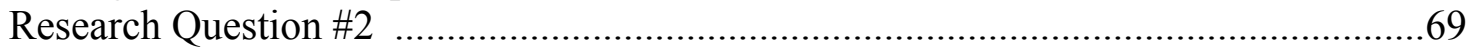

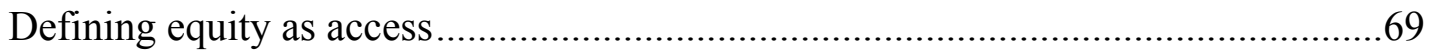

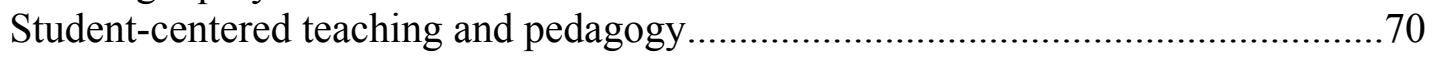

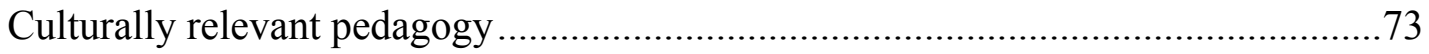

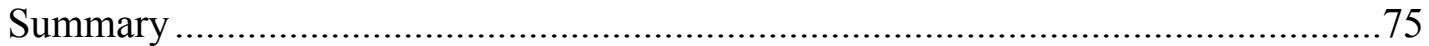

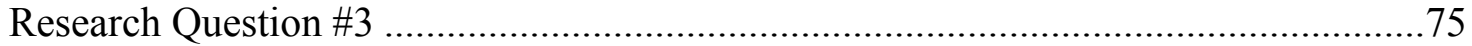

Teacher/administrator perceptions of out-of-school factors ......................................75

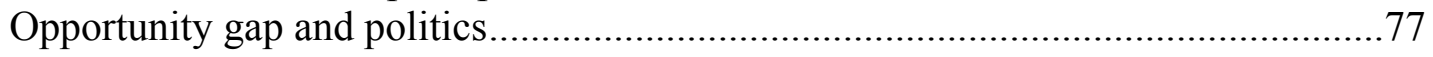

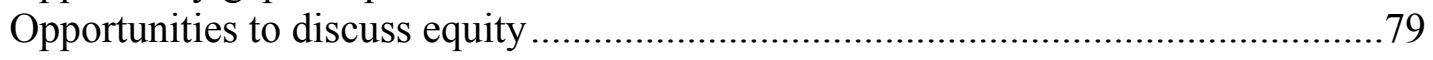

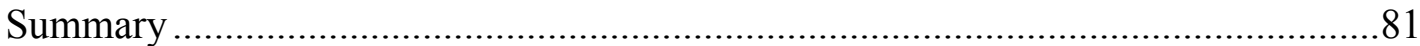

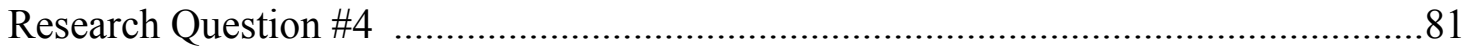

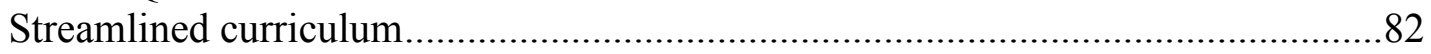

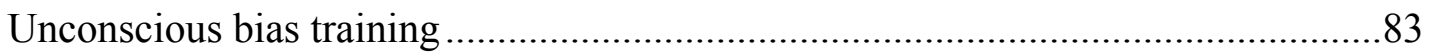

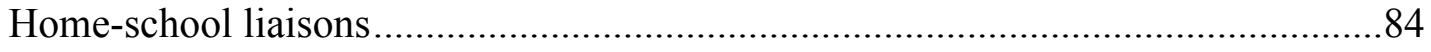

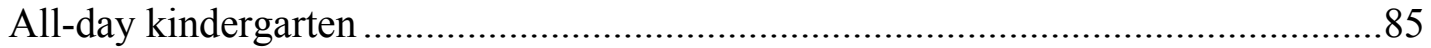

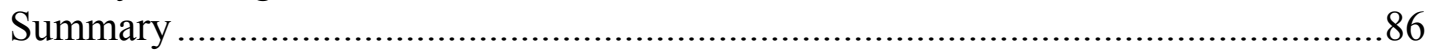

CHAPTER 5: Summary, Conclusions, and Recommendations .........................................8

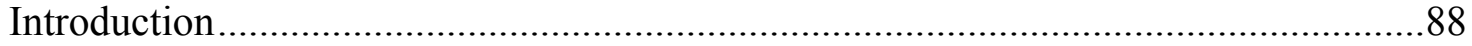

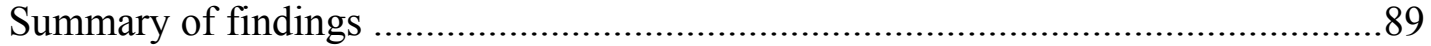

Reciprocity and the future of Ocotillo School District's journey ...............................90

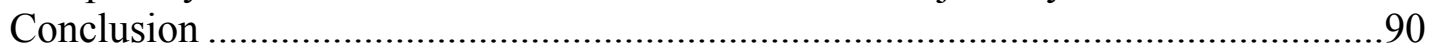

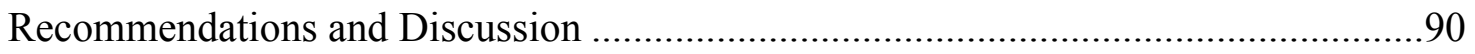

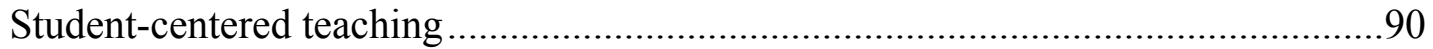

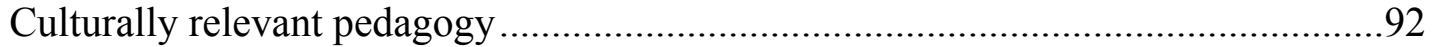

Focus on closing the opportunity gap ………………….........................................93

Opportunities to have open conversations about race and class ..................................94 
Recommendations for leadership and administrative practice

Next steps for future research

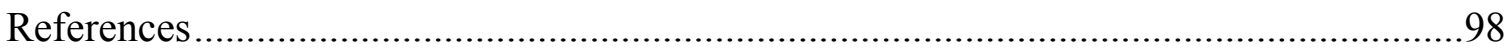




\section{LIST OF TABLES}

Table1. $\quad 2013$ California Standards Test Results............................16

Table 2. $\quad 2015$ Smarter Balanced Assessment Results-California...........................17

Table 3. International Childhood Poverty Rates............................. 19

Table 4. Pearson International Index Rankings............................20

Table 5. Participant Matrix $\quad$........................................... 54

Table 6. $\quad$ Participant Information Table..................................55

Table 7. OSD Three-Year SBAC Disaggregated Results.......................62

Table $8 . \quad$ OSD Three-Year AP Enrollment by Ethnicity.....................63

Table 9. MATD Update on Original 12 Recommendations.....................67 


\section{LIST OF FIGURES}

Figure 1. $\quad$ Literature review logical flow.................................... 14

Figure 2. Four-part case study approach................................. 50

Figure 3. Dissertation general information diagram..........................56

Figure $4 . \quad$ Summary of findings diagram ................................... 89 


\section{LIST OF ABBREVIATIONS}

CCSS: Common Core State Standards

ELA: English Language Arts

ESSA: Every Student Succeeds Act

MATD: Minority Achievement and Talent Development Task Force

OSD: Ocotillo School District

PARCC: The Partnership for Assessment of Readiness for College and Careers

PIRLS: Progress in International Reading Literacy Study

PISA: The Programme for International Student Assessment

SBAC: Smarter Balanced Assessment Consortium

TIMSS: Trends in International Mathematics Science Study 


\section{Chapter 1}

\section{Introduction}

The public education system in the United States has failed to serve its students of color and socio-economically disadvantaged students for as long as it has existed. Positive educational outcomes and opportunities for Black and Latino students have long been lacking and have not been provided at the same level as they have for White and Asian students (Haycock, 2006). Nationwide trends show that disparities in educational outcomes also exist between students from economically disadvantaged families and students from more affluent families (Haycock, 2006). While the responsibility for the lack of results in educational outcomes for large segments of American students cannot solely fall on the shoulders of the education system (Berliner, 2009; Berliner \& Glass, 2014; Coleman, 1968; Edmonds, 1986; Rutter, 1982), there are definitely factors within

the school system that can be examined and improved upon (as there is in nearly any field of study).

The comparative lack of positive educational outcomes for Black, Latino, and economically disadvantaged students has often been attributed to the lack of funding and resources available to schools that serve students of color and students from socioeconomically disadvantaged communities (Kirst \& Wirt, 2009). While school funding may be part of the issue, it is interesting to note that schools with diverse student populations that have ample resources are also underserving their students of color and economically disadvantaged students. Even in these resource rich and well-funded districts there are often huge disparities in educational outcomes between students of 
color and White and Asian students, as well as academic disparities between students that are economically disadvantaged and those that are not (National Center for Education Statistics, 2018).

One suburban school district in California (that has both a diverse student population as well as comparatively ample resources) has recently made efforts to address the disparate educational outcomes between its Black and Latino students and White and Asian students, as well as the disparate educational outcomes between its students from affluent families and students from economically disadvantaged families. The disparate educational outcomes have been occurring in this district for decades (California Department of Education, 2016) and a new superintendent decided that addressing the issue would become a district priority.

During the 2014-15 school year, the first-year superintendent of Ocotillo School District (OSD) decided to take on the challenge of addressing the disparities in educational outcomes. OSD assembled a task force to study, in depth, issues related to the district's disparate educational outcomes. The task force was comprised of teachers, administrators, classified employees, parents, and community members with the intention of identifying the root causes of the disparities in educational outcomes and proposing recommendations for actions designed to address the problems identified. The superintendent charged the task force with the assignment of making a set of recommendations for actions that the school district needed to take to address the educational disparities prevalent in the district. The committee was named the Minority Achievement and Talent Development Task Force (MATD). 
After a full year of study and discussion, the task force made recommendations aimed at reducing the disparate educational outcomes present in the district. Over the last three years the district has been implementing the task force's recommendations with the expectation that the there would be signs of improved educational outcomes for underserved students. The hope was that implementation of the recommendations would lead to improved results from underserved student populations on a variety of assessment measures including performances on state standardized tests.

\section{Background Information on the Study}

This study will focus on OSD's efforts to improve educational outcomes for its historically underserved student populations through the recommendations made by the superintendent's equity task force. To the outside world, the OSD looks like a model district that boasts some of the highest student achievement scores in the country. This is primarily because most of its students are either Asian or White, are from extremely wealthy families, or they have linguistic and family assets that match the values of traditional school culture (Haycock, 2006; Yosso, 2005). Scores on national exams put OSD students in the fifth percentile nation-wide. Eighty-five percent of students that attend Ocotillo schools go on to attend four-year universities (Ocotillo School District MATD Committee Report, 2015).

However, a deeper look at student achievement and educational outcomes in Ocotillo tells a different story, a much less-encouraging reality. Looking deeper at student achievement data (across all schools and grade levels) in OSD would reveal a distinct divide between a high achieving majority of students (predominantly White and Asian) 
from well-resourced families, and a smaller percentage of students of color from lowresourced families that are not achieving the same levels of academic success.

When examining aggregate student achievement data, one discovers that White and Asian students score higher than Black, Latino, and Pacific Islander students, and students from well-resourced family backgrounds score higher than those from lowresourced backgrounds. For example, recent SAT results show a gap of 200 points between students from families with incomes greater than $\$ 200 \mathrm{~K}$ and students from families with incomes less than $\$ 100 \mathrm{~K}$. Additionally, combined SAT scores of underrepresented minority students are about 300 points lower than those of their peers (Ocotillo School District MATD Committee Report, 2015).

The MATD Task Force identified five major problem areas within the organization and community that were labeled as root causes of the disparities in student achievement and academic outcomes for Ocotillo students. The five problem areas or clusters are listed below:

1. An underlying and unconscious narrative of bias

2. A lack of quality parent-student-school-community connections

3. Poor instructional standards and accountability

4. Poor identification and intervention structures, procedures, and policies

5. Inequitable access to resources for underrepresented minority students and students from under-resourced backgrounds

(Ocotillo School District MATD Committee Report, 2015)

After a full year of study and in-depth analysis of district policies and practices, the MATD Task Force made a total of 39 distinct recommendations for the district to consider implementing. The OSD implemented 12 of the recommendations during the 
2015-2016 school year and has continued to work towards the implementation of the remaining 27 recommendations in the subsequent school years.

In their report to the school board and community, the MATD Task Force embedded measures of success as part of the vision for change. According to the MATD Task Force report, the educational outcomes that would be used to evaluate the success of the Task Force's recommendations included:

1. An increase in the percentage of under-resourced and minority students at or above state benchmarks in reading and math.

2. An increase in the percentage of under-resourced and minority students taking advanced level courses in high school.

3. An increase in high school graduation rates for under-resourced and minority students.

4. Increased participation in mainstream clubs and student government for underresourced and minority students.

5. A reduction of under-resourced and minority students below proficient in statewide assessments.

6. A reduction of referrals of under-resourced and minority students to Alta Verde High School.

7. Growth of student connectedness for under-resourced and minority students on the California Healthy Kids Survey.

(Ocotillo School District MATD Committee Report, 2015)

Twelve recommendations were targeted for implementation during the 2015-2016

school year and are listed below:

1. Identify and administer a Pre-K to 2 nd grade diagnostic literacy and mathematics assessment and provide Tier I interventions and ongoing monitoring and intervention as necessary and assure that administrators and faculty have ready access to this data, review it regularly and use it meaningfully.

2. Commission an independent audit of current intervention programs to identify the most cost-effective.

3. Employ an Equity Coordinator to lead the development of the Equity Plan and serve as an ombudsperson for managing issues related to the education and well being of historically underrepresented students and families.

4. Launch California Teacher staff development sessions on unconscious bias, with equity trainings for all staff every four to six years. 
5. Based on the results of the diagnostic assessment for kindergarten students, provide an additional two days a week of extended or full-day kindergarten.

6. Ensure that extensive summer enrichment and after-school programming is available for historically underrepresented students.

7. Employ mathematics intervention support personnel for middle schools.

8. Identify and/or hire a Parent Outreach/Support staff.

9. Assure new hirings for teachers and administrators are representative of our district's diverse populations.

10. Create a system for obtaining, analyzing and reporting data necessary to monitor progress and report on results.

11. Strengthen existing community partnerships and foster new ones to encourage innovative supports and enrichment for underrepresented students.

12. Create clear, objective, and well-communicated information about laning decisions and waivers in mathematics in middle school and high school.

(Ocotillo School District MATD Committee Report, 2015)

According to the MATD Committee Report, the 2015 Smarter Balanced Assessment

Consortium (SBAC) results would be the established baseline for student achievement in OSD. The baseline would be used to help evaluate the effectiveness of the

recommendations and implementation of the recommendations in the MATD Task Force Report.

\section{Purpose of the Study}

This case study of Ocotillo's efforts to produce more equitable educational outcomes for its Black, Latino, and economically disadvantaged students focuses on the way teachers and site administrators at the elementary and middle school level think about equity issues, the strategies they used to address these issues, and if and how the district equity initiatives from the MATD Task Force have affected practices and thinking around equity. The research questions addressed by this study are as follows:

1. What progress has been made towards the MATD Committee's goals since its recommendations in 2015 ? 
2. What are teacher/school administrator knowledge, beliefs, and attitudes towards equity issues in education (generally) and at OSD specifically?

3. What factors do school site administrators and teachers say they have to manage when implementing initiatives aimed at reducing disparities in educational outcomes among their students?

4. Has the district initiative to reduce disparities in educational outcomes changed the way that teachers/school administrators operationalize and reflect on their practice? If so, how?

\section{Description of the Organization}

The district consists of a Pre-K program, twelve elementary schools, three middle schools, and two high schools. A Children's Hospital School located at the local university is also part of the school district. The amount of per student spending in OSD demonstrates the relatively large amounts of resources available to the schools. OSD spent an average of $\$ 14,036$ per student during the 2015-2016 school year, compared to the state average of $\$ 8,954$ per student in other unified districts in the state (Education Data Partnership, 2018).

The majority of the student population in OSD is quite affluent. The district's enrollment peaked in 1967 when it had 15,575 students. The current student enrollment is approximately 12,000 students. Of those 12,000 students about $40 \%$ are White, $33 \%$ are Asian, $11 \%$ are Hispanic/Latino, and 2\% are Black. The remaining $14 \%$ or so of students are either of mixed ethnicity or considered "other." Approximately $10 \%$ of the students in Ocotillo are considered economically disadvantaged. OSD's mission and vision statements are written below:

We are a public, Pre-K-12 school district that unites our students, teachers, staff, and parents to deliver on our collective vision by offering a rich and challenging 
academic experience to all students within a supportive community, dedicated to preparing our youth for the challenges of living in a fast-changing world.

We support all OSD students as they prepare themselves to thrive as global citizens in a rapidly changing world. We develop our students' knowledge, critical thinking, and problem solving skills, and nurture their curiosity, creativity, and resilience, empowering every child to reach his or her fullest intellectual, social, and creative potential.

About the District. OSD is a pseudonym to protect the identity of the district and its employees. The city of Ocotillo is affluent yet has a diverse student population in terms of both ethnicity and socio-economic status. A court-ordered desegregation act buses students in from the city of East Ocotillo, which is far less affluent than Ocotillo. East Ocotillo is on the other side of an interstate highway and its residents are predominantly Latino, Black, and Pacific Islander. Ocotillo's residents are predominantly White and Asian. The northern side of the city of Ocotillo is the most affluent as it is close to the downtown businesses and the university. On the southern side of the city there is a mobile home park and lower-income apartment housing along the railroad tracks. Much of the ethnic diversity and economic diversity within the city of Ocotillo is on the southern side of the city. The schools that serve the southern end of the city have a more diverse demographic in terms of ethnicity and socio-economic status.

District setting and historical perspective. The facilities at the school sites are updated and modern compared to many other districts in the state. The high schools have more updated facilities compared to the elementary and middle schools. The hallways of the district offices are lined with exhibits of student artwork from all over the district. Ocotillo has a very prolific art program and it is a value of the community. During the economic downturn, many school districts had to downsize their art and music programs. 
Ocotillo did not have to do this and was able to maintain its art and music programs. Since there is little pressure from the community to improve academic results, the art and music programs have been able to thrive in Ocotillo.

OSD was founded in 1893, two years after the opening of the local university, which is directly across the street from the district offices and one of the two high schools. The influence of the university on the district is extensive. The administrative building at Ocotillo High School used to be part of the university's campus and it shares the same architecture style as many of the college campus' buildings. The Ocotillo High School parking lot is used during college football games and generates funding for the athletic program and other clubs/student organizations.

Many students in the district live on the college campus in university housing as children of professors. One of the elementary schools is even on the university's campus. Being in a college town leads to an interesting dynamic, as a large portion of the parent population is highly educated. Being in a college town also adds an international flair to the student population, as many students are the children of traveling professors from all over the world. More than 20 different languages are spoken on the various Ocotillo campuses and many of the international students only stay in the district for 1-2 years before they return home and make way for new traveling professors and their families.

District values. The organization that is OSD talks extensively about its high levels of academic achievement, and its standardized test scores rank it as one of the highest achieving school districts in the United States. The dominant values in the district seem geared towards maintaining a highly competitive academic environment where student 
achievement is of the highest importance. Members of the organization seek to maintain OSD's status as a high achieving district by consistently referring to the academic accomplishments of the students and comparing themselves to other districts. Everything in Ocotillo seems to be competitive and students are constantly being showcased for accomplishments and awards they have received in academics, art, music, or athletics.

\section{Summary}

This study aims to describe and understand the gains made on the recommendations of the MATD Task Force and detail the remaining challenges for OSD as they continue on their desired journey towards more equitable educational outcomes for their students. This study will not be looking to assign blame for disappointing educational outcomes on OSD or any other educational institution. The responsibility for improving educational outcomes for historically underserved students extends well beyond the boundaries of academic institutions and is a challenge facing our society at large. The hope is that from this study, other districts can learn from the mistakes and successes of OSD in order to chart their own course towards more equitable educational outcomes for their students.

The affluent OSD adopted several recommendations designed to address educational disparities. Three years into implementation, there has not been much progress towards the committee's stated goals of "an increase in the percentage of under-resourced and minority students at or above state benchmarks in reading and math" and "a reduction of under-resourced and minority students below proficient in statewide assessment." These data suggest the initiative has not been a success, yet my qualitative research found gains made in several areas evidenced by changes in teachers' thinking about equity and their 
approach to educational disparity. Those gains include embracing and implementing a student-centered approach as well as culturally relevant pedagogy. Furthermore, the study found that teachers would like more discussion of equity issues, which evidence suggests is lacking. These findings support literature that recommends moving away from high stakes testing as an indicator of school/student success and instead embracing structural changes that include addressing out-of-school factors and the opportunity gaps present among the district's students.

The next chapter will conduct a review of literature pertinent to equity issues and student achievement. The three main sections to the following chapter will inform the case study of OSD and its equity initiatives.

\section{Definitions of Terms Used in This Study}

Economically disadvantaged students: are a disaggregated group made up of students eligible to receive free or reduced cost lunches (California Department of Education, 2016).

Historically underserved students: in this school district will be defined as students from groups that have not been provided with adequate access to instruction and opportunities to achieve the same academic achievement levels as others. In the context of this school district, Asian students are not considered historically underserved.

Educational outcomes: A multitude of factors pertaining to student achievement (including performance on state and district assessments), enrollment in Advanced Placement courses, graduation rates, participation in clubs, and connectedness to school (based on survey results). 
Race/ethnicity: is determined by what parents have identified on a student's school registration form.

Students of color: are defined in this study as Black and Latino. The MATD Committee report also refers to this group as underrepresented minorities.

Opportunity gap: refers to the ways in which race, ethnicity, socioeconomic status, English proficiency, community wealth, familial situations, or other factors contribute to or perpetuate lower educational aspirations, achievement, and attainment for certain groups of students (Ladson-Billings, 2006).

Educational equity: is a measure of fairness and opportunity in education, which means that factors specific to one's personal conditions should not interfere with the potential of academic success (Coleman, 1968).

Consequential validity: for an assessment to have consequential validity it must not have negative social consequences. Consequential validity can help identify tests that are not measuring things they are supposed to be measuring (Popham, 1997). 


\section{Chapter 2}

\section{Literature Review}

Measuring student progress has long since been at the core of teaching, learning and the educational process. Methodologies (ranging from standardized tests to in-class formative assessments) on how to measure student learning have been varied and discussed for years. With the current student evaluation practices in the United States, disparate outcomes have emerged among groups of students of different ethnicities and of different parent income levels. This literature review will examine explanations for the disparities in student achievement among various student ethnic groups as well as present different strategies educators have employed to achieve more equitable outcomes for all segments of their diverse student populations.

The literature review described in Figure 1 begins with a global view of equity in American education as well as the larger political and historical context related to the issue. The next section of the literature review will address in-school practices that have been researched and used to address educational disparities in American schools. In the final section, the literature review will detail out-of-school factors affecting educational outcomes beginning with empirical factors and concluding with conceptual factors. 


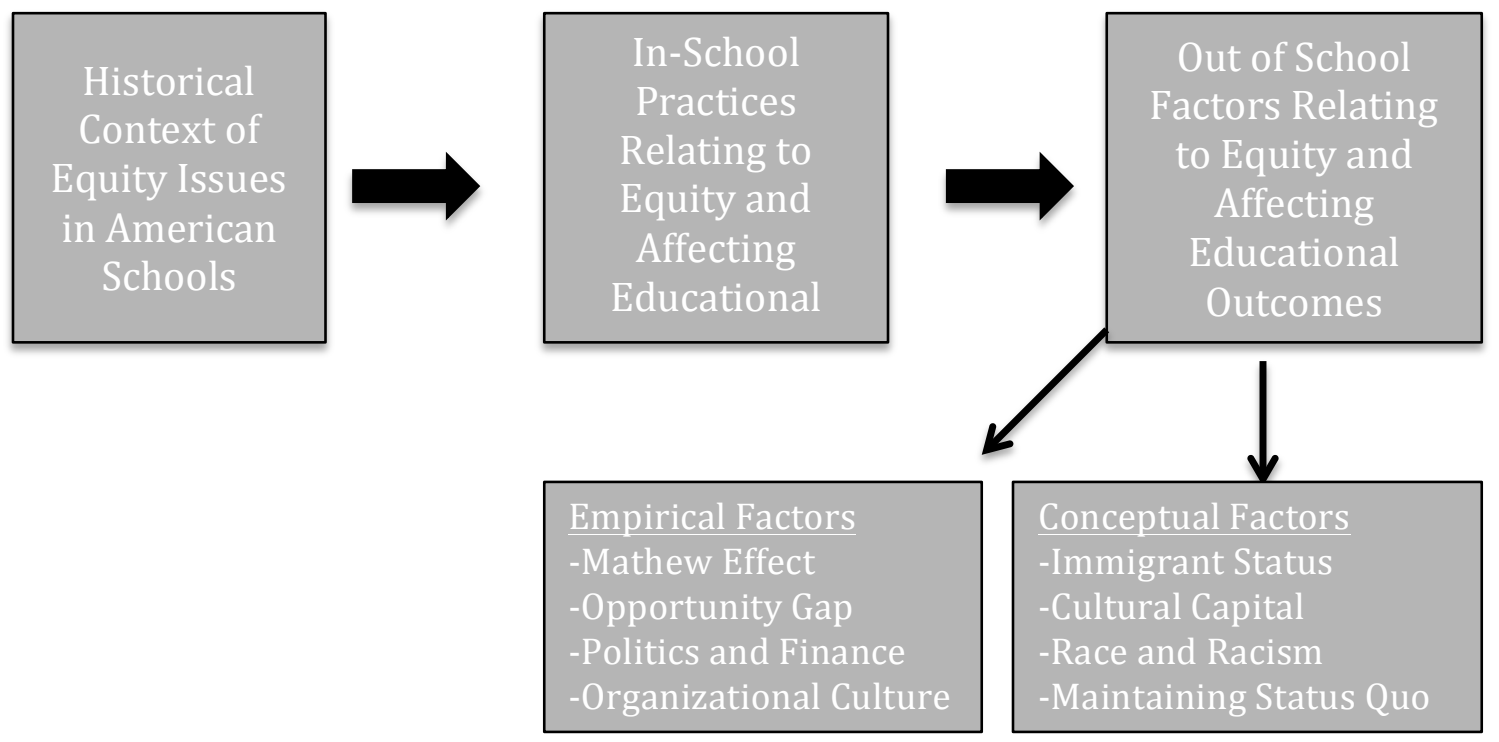

Figure 1. The figure shows the logical flow of the review of literature.

My study is focused on one affluent school district's recent efforts to meet the needs of its underserved student populations. The literature review will begin with an analysis of student assessment data from California, including the transition from the California Standards Test (CST) to the Smarter Balanced Assessment Consortium (SBAC). The literature review will then give the historical background and context explaining the recent push for accountability and assessment measures in American education. Finally, the literature review will conclude with a summary of the research on effective strategies for attaining more equitable student outcomes in education.

\section{Historical Context}

The following sections will provide background information and historical context for the ongoing equity issues in the American education system. The sections will focus on the role of standardized testing and the impact it has had on American students. 
Disparate outcomes on standardized tests. One outcome of the underfunded federal mandate called the "No Child Left Behind Act of 2001" (and the latest reform movements in education) was that large amounts of quantitative data points were generated by requiring standardized testing for all American students. The quantitative data created from mandatory yearly summative assessments for millions of American students showed what some scholars were already noticing, a disparity in academic achievement among various student groups in the country (Haycock, 2006). The data generated by the extensive assessment practices shed light on poor performances from impoverished and minority students and the deep inequities in American public education, including clear disparities in educational outcomes (Bowles \& Gintis, 2012; Haycock, 2006; Trujillo, 2013).

The disparities in student performance, on the California Standards Test results from 2013, among various ethnic groups and among children with different family income levels are displayed in Table 1. 
Table 1

2013 California Standards Tests Results

\begin{tabular}{|l|l|l|l|l|l|l|}
\hline & $\begin{array}{l}\text { African } \\
\text { Amer./ } \\
\text { Black }\end{array}$ & $\begin{array}{l}\text { Hisp./ } \\
\text { Latino }\end{array}$ & White & Asian & $\begin{array}{l}\text { Econ. } \\
\text { Disadvantaged }\end{array}$ & $\begin{array}{l}\text { Not Econ. } \\
\text { Disadvantaged }\end{array}$ \\
\hline $\begin{array}{l}\text { Avg. \% of } \\
\text { students } \\
\text { Proficient or } \\
\text { Advanced in } \\
\text { English } \\
\text { Language } \\
\text { Arts (Grades } \\
\text { 2-7) }\end{array}$ & $46 \%$ & $73 \%$ & $79.5 \%$ & $46 \%$ & $77 \%$ \\
\hline $\begin{array}{l}\text { Avg. \% of } \\
\text { students } \\
\text { Proficient or } \\
\text { Advanced in } \\
\text { Math } \\
\text { (Grades 2-7) }\end{array}$ & $46 \%$ & $54 \%$ & $74.5 \%$ & $86 \%$ & $53 \%$ & $77.5 \%$ \\
\hline
\end{tabular}

Note: Table adapted From California Department of Education, 2016

Table 1 shows an achievement gap in that White and Asian students scored markedly higher in both English Language Arts and Math than their Black and Latino peers. The gap was also apparent in that students from economically disadvantaged backgrounds scored lower than students that were not economically disadvantaged.

When the Common Core Sate Standards (CCSS) movement started to take hold and the standardized tests were adopted nationally, most states chose to test with either the SBAC or the Partnership for Assessment of Readiness for College and Careers (PARCC). Regardless of which test was used, a similar pattern of disparities in student achievement among ethnic subgroups and economic status levels held true. Table 2 shows SBAC results in California for 2015. 
Table 2

2015 Smarter Balanced Assessment Consortium Results-California

\begin{tabular}{|l|l|l|l|l|l|l|}
\hline & $\begin{array}{l}\text { Black/ } \\
\text { African } \\
\text { American }\end{array}$ & $\begin{array}{l}\text { Hispanic } \\
/ \text { Latino }\end{array}$ & White & Asian & $\begin{array}{l}\text { Econ. } \\
\text { Disadvantaged }\end{array}$ & $\begin{array}{l}\text { Not Econ. } \\
\text { Disadvantaged }\end{array}$ \\
\hline $\begin{array}{l}\text { Percentage } \\
\text { of students } \\
\text { who met or } \\
\text { exceeded } \\
\text { standards } \\
\text { in ELA }\end{array}$ & $28 \%$ & $32 \%$ & $61 \%$ & $72 \%$ & $31 \%$ & $64 \%$ \\
\hline $\begin{array}{l}\text { Percentage } \\
\text { of students } \\
\text { who met or } \\
\text { exceeded } \\
\text { standards } \\
\text { in Math }\end{array}$ & $16 \%$ & $21 \%$ & $49 \%$ & $69 \%$ & $21 \%$ & $53 \%$ \\
\hline
\end{tabular}

Note: Table adapted From California Department of Education, 2016

Recent accountability/reform movements. Recent scholarship contends that the latest public school reform movements and the push for standardized testing is part of a separate concern from an aging White population to show that the public education system is failing, so that they can slowly privatize education and reduce their tax burden (Glass, 2008). The motivation behind increased support for high stakes testing comes from the recent demographic trends in American public schools, where the majority of students are now Black and Brown and educating them is of less interest or concern to aging White taxpayers (Glass, 2008). The rise in the number of charter schools in America is added evidence that this phenomenon is indeed taking place. The percentage of charter schools in America increased from 4\% in 2004-05 to 7\% in 2014-15 (National Center for Education Statistics, 2018). This trend suggests that the reform movements in education and the push for more standardized testing were part of a larger effort to show 
that the public education system in America was failing and to demonstrate a "manufactured crisis" (Berliner \& Biddle, 1995).

In fact, some academic researchers contend that the United States doesn't have an education problem at all, it has a poverty problem, an income disparity problem, even a tax structure problem, that manifests itself as problems in educational outcomes (Berliner, 2009). These data present the view that the American public education system was actually doing quite well, all things considered (Berliner \& Biddle, 1995).

In their view, out of school factors associated with poverty, such as violence (and the related trauma), and the lack of access to decent health care, housing, and/or nutrition have significant negative impacts on academic achievement (Berliner, 2009). According to Berliner, until these out of school factors are addressed not much more can reasonably be expected from the American public education system (Berliner, 2009).

Comparing the American public education system to education systems in other countries reveals that the American education system is actually doing relatively well considering the prevalence of childhood poverty in the country. Table 3 shows childhood poverty rates in several countries. Table 4 shows national rankings on international tests. 
Table 3

International Childhood Poverty Rates

\begin{tabular}{|l|l|}
\hline Percentage of Relative Childhood Poverty & Country \\
\hline 4.7 & Iceland \\
\hline 5.3 & Finland \\
\hline 6.1 & Cyprus \\
\hline 6.1 & Netherlands \\
\hline 6.1 & Norway \\
\hline 6.3 & Slovenia \\
\hline 6.5 & Denmark \\
\hline 7.3 & Sweden \\
\hline 7.3 & Austria \\
\hline 7.4 & Czech Republic \\
\hline 8.1 & Switzerland \\
\hline 8.4 & Ireland \\
\hline 8.5 & Germany \\
\hline 8.8 & France \\
\hline 8.9 & Malta \\
\hline 10.2 & Belgium \\
\hline 10.3 & Hungary \\
\hline 10.9 & Australia \\
\hline 11.2 & Slovakia \\
\hline 11.7 & New Zealand \\
\hline 11.9 & Estonia \\
\hline 12.1 & United Kingdom \\
\hline 12.3 & Luxembourg \\
\hline 13.3 & Canada \\
\hline 14.5 & Poland \\
\hline 14.7 & Portugal \\
\hline 14.9 & Japan \\
\hline 15.4 & Lithuania \\
\hline 15.9 & Italy \\
\hline 16.0 & Greece \\
\hline 17.1 & Spain \\
\hline 17.8 & Bulgaria \\
\hline 18.8 & Latvia \\
\hline 23.1 & USA \\
\hline 25.5 & Romania \\
\hline Percentage of children living in households & (UNICEF, 2016) \\
with equivalent income lower than $50 \%$ of & \\
\hline the national mean. & \\
\hline & \\
\hline & \\
\hline
\end{tabular}


Table 4

Pearson International Index Rankings

\begin{tabular}{|l|l|l|}
\hline Country & Rank & Pearson-International Index Score \\
\hline South Korea & 1 & 1.30 \\
\hline Japan & 2 & 1.03 \\
\hline Singapore & 3 & 0.99 \\
\hline Hong Kong-China & 4 & 0.96 \\
\hline Finland & 5 & 0.92 \\
\hline United Kingdom & 6 & 0.67 \\
\hline Canada & 7 & 0.60 \\
\hline Netherlands & 8 & 0.58 \\
\hline Ireland & 9 & 0.51 \\
\hline Poland & 10 & 0.50 \\
\hline Denmark & 11 & 0.46 \\
\hline Germany & 12 & 0.41 \\
\hline Russia & 13 & 0.40 \\
\hline United States & 14 & 0.39 \\
\hline Australia & 15 & 0.38 \\
\hline
\end{tabular}

Note: The Pearson index score uses data sets such as PISA (Programme for International Student Assessment), TIMSS (Trends in International Math and Science Study), and PIRLS (Progress in International Reading Literacy Study) together with individual country data such as literacy and graduation rates. A higher index score indicates a better ranking. (Pearson Index, 2014).

As indicated in Tables 3 and 4, the percentage of children living in poverty in the United States is large (23.1\%). Given this outcome, the American school system actually did quite well on international tests, especially when one takes into account the extent of childhood poverty in the United States. Childhood poverty in the United States has grown significantly over the last decade and it is surprising that a country of so much wealth has so many impoverished children (Mitchell, 2011). Critiques that the American education system is failing seem unfounded and manufactured for political purposes (Berliner \& Biddle, 1995). While it is true that Black and Latino as well as economically disadvantaged students in California are performing relatively poorly on the state tests, the outcomes could have been predicted from the outset as part of an inequitable 
economic system resulting in great income disparities across subgroups. Using rhetoric citing the need to improve schools and accountability to ensure equitable outcomes, the climate to introduce vouchers, charter schools, and additional private alternative schools is being created (Schaffter, 2001). According to critics, this phenomenon is actually leading to American schools slowly re-segregating along racial lines and it is a destabilizing force being used to dismantle the public education system (Trujillo, 2013).

Standardized assessments as a sorting tool. A major concern in the American school system is that too much emphasis has been placed on results from standardized testing which have been used as a tool to preserve the status quo and traditional societal hierarchies (Trujillo, 2013). Research findings indicate that high stakes testing negatively impacts students of color at a higher rate by lowering self-esteem and contributing to increased drop out rates (Brewer, Knoeppel, \& Lindle, 2015). In the American school system, so many educational opportunities are based on the results of standardized tests including college admission, high school graduation, and access to advanced courses. These assessments do not hold consequential validity and therefore are not as valid as some perceive them to be, thus debunking the myth that high stakes assessments are useful in truly assessing student growth or academic achievement (Brewer, Knoeppel \& Lindle, 2015). The unintended consequence of high-stakes testing is that it negatively impacts underserved student populations in multiple ways and high stakes tests are not necessarily an accurate measure of academic achievement (Popham, 1997). 
The accountability systems as they currently exist in California can be considered at least partly responsible for the inequities in the school system, but they are the reality that educators face. It is ill advised to use a single test score (or a single-system battery of tests) as the main basis for important educational decisions about individuals or groups (Hamilton, 2003). Standardized testing is often advertised as a way to achieve racial equality, however it is the testing system that actually expands the divide in equity ( $\mathrm{Au}$, 2016).

Summary of historical context. Improving student outcomes for underserved student populations is a massive undertaking, as reversing decades of inequity will take time. While I like using the term "underserved" to address the equity issues that American students face (because this term places the responsibility of improving outcomes on the educators and not the students and their families), there is definitely an uphill climb to attain more equitable outcomes which will not come easily. High stakes testing is designed to preserve the status quo and to continue to produce inequitable outcomes, which maintain historical power structures (Trujillo, 2013). Assessment is a necessary tool for educators, but the way the high-stakes assessments can be used to limit opportunities for underserved students populations needs to be reconsidered, especially since standardized assessments are often biased and/or unreliable (Popham, 1997).

To make changes to an educational system that will result in more equitable outcomes for all student populations will take years. It will also have to be a coordinated effort by many members of an organization. Because of this, OSD's goals regarding equity are worthy of study. Unlike many districts around the state of California, Ocotillo certainly 
has the resources to take on a challenge of this magnitude.

\section{In-School Practices Relating to Equity}

Educational researchers have developed strategies and methods for addressing and beginning to undo the historical and systematic damage done to students of color and underserved student populations. The following sections will discuss in-school practices used by schools and districts that have had success in reducing the disparities in educational outcomes for their underserved student populations. I will begin by discussing student-centered leadership and teaching, followed by a discussion of culturally relevant pedagogy.

Student-centered leadership and teaching. If more equitable outcomes for American students are truly desired, a student-centered philosophy and approach needs to be embraced by both the teachers and the leadership (Robinson, 2011). A studentcentered approach would positively impact educational outcomes for all students, including historically underserved student populations, in many ways (Hattie, 2012). Student-centered teaching incorporates all of the underpinnings of good teaching in which lessons can be swapped, modified, and built upon in any direction (Nave, 2015). A student-centered teaching and administrative philosophy is built on the premise of teacher flexibility and is designed to offer all students the rich variety of educational opportunities needed to develop their foundational knowledge and skills, all of which are needed to maximize learning outcomes (Nave, 2015). These foundational skills will include opportunities for students to be innovative and creative with technology. 
Additionally, the shift towards student-centered teaching would use technology as a tool to showcase student work and share student knowledge (Nave, 2015).

A student-centered approach would have a high impact on learning as teachers will be pushed to re-think and re-design their lessons to move from single concepts to multiple concepts within a lesson so that their students have opportunities to relate to their learning and construct and reconstruct new knowledge and ideas (Hattie, 2012). A school and district's academic programs should be built on student choice. In offering student choice, schools can change the mind frames of the learners involved and positively impact student learning (Hattie, 2012). The focus should be to create a learning classroom where every child's potential to learn is celebrated and valued (Senge et al., 2012).

Instructional coaching is another high-impact and research-based practice that can maximize teacher education and training when effectively implemented. Every school site should have an instructional coach hired to promote and facilitate reflective practices between teacher teams which have been designed to assess and improve the quality of teaching and learning within the classroom (Senge et al., 2012). Teachers should be given release time to observe other teachers, plan engaging lessons tailored to their students' needs, and reflect on their own practices while collaborating with other teachers and the site coach (assuming that organizational structures for coaching cycles are present). Adjusting instruction to meet student needs has been found to have a positive impact on student achievement (Wolfe, Steinberg \& Hoffman, 2013). 
A student-centered approach would focus on utilizing pedagogical approaches that increase student achievement by maximizing student-to-student interactions. Increasing student-to-student interactions has been proven to show a positive impact on learning (Wolfe, Steinberg \& Hoffman, 2013). Students should be engaged in a project-based curricula leading to culminating projects that can be shared with classmates at the end of academic terms. Culminating projects and portfolios are powerful ways for students to demonstrate their learning and have proven to have a positive impact on student achievement (Robinson, 2011).

Culturally relevant pedagogy. In many cases, educational research has shown that carefully designed lesson planning (using pedagogical practices) based on the knowledge that students already come to classrooms with can boost academic outcomes for all students, including students of color and economically disadvantaged students. The teaching strategy of studying the backgrounds of students to design lessons that are more relevant for the learners has shown improved academic outcomes for students of color and economically disadvantaged students (Ladson-Billings, 1995). This practice is referred to by some researchers as "culturally relevant pedagogy" and entails teachers becoming qualitative researchers who study their students (even visiting their homes), in order to learn about students' family dynamics and the depth of their background knowledge. In doing this, teachers can design their lessons so that they are more engaging and participatory for students because they draw on the assets and cultural knowledge that children bring from home to school (González, Moll \& Amanti, 2006). This is particularly important for students of color and students that are economically 
disadvantaged. Using culturally relevant pedagogy changes the dynamic of the classroom by creating a more symmetrical relationship between teachers and the families that they serve and in doing so, benefit historically underserved student populations (González, Moll \& Amanti, 2006).

Efforts to connect with families as a way to better meet the needs of underserved student populations have been extended to the administrative level of the education system. These efforts represent a commitment from school leadership to shift from deficit thinking to asset-based perspectives about students, families, and communities (Green, 2017) and are referred to as "community-based equity audits." This approach is based on developing strong relationships and partnerships between schools and the families and communities that they serve. A community-based equity audit is an approach that can assist school leadership in designing systems that benefit both the school and the community. The approach requires school and district leaders to reflect on their own positionality and practices by integrating the community and learning and working with them in partnership (Green, 2017).

In order to unlock the power of culturally relevant pedagogy, a mindset that embraces and celebrates cultural dignity needs to be adopted by the educators involved. The need to unify into a school community is necessary, but it should not be done at the expense of diversity. The similarities and differences between diverse student populations are important and should be celebrated by a school community (Garcia \& Öztürk, 2018). The asset-based approach to diversity is a mindset that should be recognized and understood by educators. Oftentimes, historically underserved student populations are 
viewed through a deficit lens by the school system, but this is simply a matter of perspective and bias. The historically underserved student population of Latino students is often viewed though a deficit lens. Doing this overlooks the many assets that Latino students bring to a school community. The fact that Latino students often bring many favorable cultural and linguistic assets (such as strong work ethic and positive attitudes towards education) to a school community is often overlooked (Garcia \& Öztürk, 2018).

Equity efforts in American schools. One of the seminal works in the area of achievement gap research was presented at the 2008 Annual Conference of the Achievement Gap Initiative at Harvard University in a report called, Raising Achievement and Closing Gaps in Whole School Systems: Recent Advances in Research and Practice (Ferguson, Hackman, Hanna \& Ballantine, 2008). The report outlines seven strategic practices that are used by districts proficient in reducing their own achievement gaps. The seven practices discussed in the report are listed below:

1. Leadership that combines passion with competence.

2. Clear, shared conceptions of effective instruction.

3. Streamlined and coherent curriculum.

4. Organizational structures and personnel that embody capacity to teach and motivate adults.

5. Patient but tough accountability.

6. Data-driven decision making and transparency.

7. Community involvement and resources.

(Ferguson, Hackman, Hanna \& Ballantine, 2008)

Other scholars have built on the work presented at the achievement gap conference at Harvard University in 2008 and have made further recommendations regarding the achievement gap dilemma. Olszewski-Kubilius and Clarenbach (2014) made the following recommendations to districts wanting to boost the academic achievement of 
their underserved student populations and increase the number of Black and Brown students in gifted programs.

1. Match identification procedures and programing (for underserved students) with level of developed talent.

2. Build awareness about the diversity of high-ability learners.

3. Attend to the non-cognitive factors affecting student achievement.

4. Provide a challenging and enriching curriculum.

5. Deliberately cultivate support networks for students (of color).

6. Create program components and partnerships to equalize opportunities.

Continuing to build on the equity minded work of addressing the disparities in academic outcomes between various student groups includes research supporting a school accountability approach that focuses on meaningful student learning, (not necessarily correlated to state tests) high quality training and professional development aimed at building teacher capacity, and distribution of resources specifically targeting underperforming student groups (Darling-Hammond, Wilhoit, \& Pittenger, 2014).

Another effective research-based approach for achieving more equitable outcomes for underserved student populations includes the creation of community schools. Community schools are generally defined as places where school and community agencies partner together to serve student populations that are underperforming. These institutions take an integrated approach that combines together to focus on academics, health and social services, youth and community development, and community engagement (Oakes, Maier \& Daniel, 2017). The approach has proven to be effective for students of all backgrounds, but has been shown to be particularly effective in school communities where poverty and racism are additional challenges facing students. 
Community schools can act as a supplement to what typical schools provide and focus on families that have access to fewer resources (Oakes, Maier \& Daniel, 2017).

Transformative ruptures. The challenge for districts desiring more equitable student outcomes is creating new systems and operationalizing the research-based methods for undoing the damage and results of the past. Disrupting inequitable practices and oppressive structures in education is a challenging task that will take time, but it can be done through ongoing transformative ruptures of courageous teachers and administrators (Bernal \& Aleman, 2017). Any moment in which systematic inequity is challenged through the questioning of the status quo can be considered a transformative rupture. It will take numerous interactions like these (by many educators) to begin to cause meaningful shifts in the American educational system.

\section{Empirical Data on Factors Affecting Educational Outcomes}

Besides poverty and other related out-of-school factors, numerous scholars have provided a variety of explanations for the disparate outcomes in student achievement among ethnic groups and among different parent income levels. The following sections will examine other factors that explain disparate educational impacts and outcomes for ethnic subgroups and economically disadvantaged students. I will begin by examining the "Mathew effect" before going into a discussion of the opportunity gap in education. I will then discuss political and financial factors as well as organizational forces that create additional barriers for change efforts.

Mathew effect (The rich get richer). Some of the patterns of inequity that have become apparent in school systems around the country can be explained by what 
sociologists refer to as the "Mathew effect." This phenomenon as it relates to educational outcomes describes the cumulative advantage that groups coming into the school system already "ahead" maintain as they go through the system (Merton, 1968). Researchers that have studied this phenomenon in schools have found that students who are identified as low-achieving when they enter school will fall exponentially further behind as they move through the system and the gaps between high-achieving and average-ability students stay they same or grow larger as those groups move through the school system (Morgan, Farkas \& Hibel, 2008).

The explanations for these effects have been attributed to subtleties in the amounts of praise and instructional attention that "better" students receive from their teachers and the spiral of positivity, increased motivation, and self-efficacy that develops within those students (Stanovich, 1986). Over time, students that receive the additional praise and instructional attention begin to internalize positive connections between their classroom status and their learning. Further accelerating and exacerbating the growing disparities is the common instructional practice of ability grouping that usually begins in the lower primary grades and continues through high school graduation. When ability grouped, the "higher" groups of students benefit from both the elevated levels of academic discourse and expectations, as well as the boost in confidence from being placed in the group (Pallas, Entwisle, Alexander \& Stluka, 1994).

The opportunity gap. Economically disadvantaged students are experiencing an opportunity gap. Ladson-Billings (2006) defines the "opportunity gap" as an educational debt. The educational debt refers to inequalities in health care, early childhood 
experiences, out-of-school experiences, and economic security that contribute to the achievement gap. According to Gandara and Contreras (2010), low-income students, especially Latino students, have fewer options for early childhood education. African American and Hispanic students are also more likely to feel unsafe in schools or on their way to school compared to white students. Ladson-Billings (2006) argues that in order to eliminate the achievement gap that exists between different racial and socioeconomic groups, we must first address this educational debt from an additive, not subtractive perspective. Many times, economically disadvantaged students have not had the opportunity to attend pre-school which sets them behind academically when they start kindergarten. They also do not have the opportunity to experience enrichment classes during the summer or pay for private tutors to catch up and make academic progress.

The opportunity gap is a contributing factor to many of the disparate outcomes present in the education system, including over-identification of students of color in special education, under-identification of students of color in gifted education, higher suspension rates for students of color, and a lower number of students of color that participate in extracurricular activities (Milner, 2012). Because educational systems have failed to address this opportunity gap, the advantages some student groups have over others continues to exist. Educators often carry deficit mindsets, lower expectations, or even negative expectations for students of color and these expectations eventually become self-fulfilling prophecies (Milner, 2012). The impact of the opportunity gap can cause many students to act out or lose interest in their schooling because there is a lack of relevance perceived by the students (Milner, 2012). 
Politics and finance. Competition for resources has been going on in the United States since before it became an independent nation. Racial dynamics often play into the distribution of resources and the parties with control of the resources tend not to distribute them equitably. The wealth and political power in the United States is disproportionately distributed to whites and away from most minority groups of color. School systems reflect these inequalities and some scholars would say that they are designed to replicate them (Brewer, Knoeppel, \& Lindle, 2015). Many schools boards in districts with large amounts of wealth view themselves as elite councils—-small in size, who see themselves as guardians of public funds (Kirst \& Wirt, 2009). In other words, those in charge view themselves as defenders of the status quo and help perpetuate the continued inequalities in educational outcomes, which ensures that they never get rectified.

Creating more compassionate and empathetic citizens and voters is critical and can lead to policies that promote equity. Poor students require significantly more funding to educate. The average state provides 17.2 percent more funding for a poor student than for a non-poor student, whereas existing research suggests that the cost of educating a poor student is at least 100 percent higher than that of educating a non-poor student (Yinger, 2004). The main reasoning for all of the additional costs for educating poor students are out-of-school factors related to poverty such as low birth weight and nongenetic parental influences, inadequate medical, dental, and vision care, food insecurity, environmental pollutants, family relations/family stress, and neighborhood characteristics (Berliner, 2009). 
Improving educational outcomes for economically disadvantaged students will inevitably cost a significant amount of money from taxpayers. Therefore, those in control of the resources need to be financially committed to doing so. There simply does not seem to be a political commitment to more equitable outcomes in education.

Competitions for scarce resources in public education seem to be adding fuel to the racial tensions that remain hidden under the surface of society. As the older white tax base lives longer and falls deeper into debt, many white American citizens are becoming more and more reluctant to fund schools that are educating large numbers of children of color (Glass, 2008). This becomes yet another obstacle school systems face when attempting to create more equitable outcomes for their students.

Changing organizational culture. The successful roll out of initiatives such as the MATD Task Force recommendations are often dependent on the ability of the organization to shift its culture as well as the mindset of the employees to fully embrace the larger goal or mission. Leadership can do this effectively by engaging both the positive and negative skeptics within the organization (Auster \& Ruebottom, 2013). When it comes to equity challenges in schools, any district seeking to reduce disparities in academic outcomes among its various student populations will only be as successful as the employees entrusted in carrying out the initiatives at the site level (principals/site leaders and teachers). Doing so would require buy-in from both the leadership of the organization, as well as a critical mass of employees at all levels of the organization. The tendency for people who work in large organizations is to resist changes (Battilana \& Casciaro, 2013). Battilana and Casciaro (2013) categorize members of an organization 
intending to make shifts into three groups; "early adopters," "fence-sitters," and "resisters." The ability of an organization to successfully enact change within is a difficult task and requires the leadership and influential members to use strategic approaches that target "fence sitters" to build a critical mass that will eventually lead to "resisters" joining the movement or leaving the organization (Battilana \& Casciaro, 2013).

\section{Conceptual Research on Factors Affecting Educational Outcomes}

The following sections discuss additional factors that have an impact on educational outcomes. Educational research has proven the existence of these factors, but they are often complex in nature and challenging to quantify. I will begin by discussing immigrant status and cultural capital as factors affecting educational outcomes. I will then discuss the role of racism and institutional forces leading to the preservation of the status quo.

Immigrant status. The United States has historically been and continues to be a nation of immigrants. Academic researchers have identified that immigrant status can indeed impact educational outcomes in American schools. As students continuously immigrate and move into American schools from various parts of the globe, their experiences shape the way that they interact with the school system and are treated by the school system. Many first generation American students (particularly students of color) fight against the dominant culture they are immersed in by rejecting their schooling because of the lack of acceptance of their primary culture. These students push back because they correlate academic achievement with "acting white" (Valenzuela, 1999). 
Immigrant students, or students from families that are recent immigrants to America, often react negatively to the lack of acceptance from the dominant culture. The lack of acceptance can come from either peers or the educators they encounter in their school life. The lack of acceptance can push immigrant students, or students whose families have recently immigrated to the country, to become less interested in learning what their teachers are trying to convey (Valenzuela, 1999), rather than education being additive, the vast cultural differences result in subtractive schooling.

Cultural capital. Besides having immigrant status, possessing cultural capital in the dominant culture is a factor that can lead to higher levels of academic achievement in American schools. Cultural capital plays a significant role in academic outcomes and is defined as a combination of aspirational, linguistic, familial, social, navigational and resistant components leading to more opportunities in society (Yosso, 2005). Lacking cultural capital should not be viewed as a deficiency, but it should be recognized that the cultural capital of the dominant culture is more valued by the school system than the cultural capital of historically underserved student populations.

Students from families with sufficient cultural capital (matching that of the ruling class) and an understanding of the dominant culture in America have an easier time navigating successfully through the school system (Yosso, 2005). The ease in which a student moves through the school system is referred to as navigational capital. Linguistic capital is another form of cultural capital that can lead to more positive educational outcomes. Having the language and confidence that fits with the linguistic norms of the dominant culture puts students from families that lack linguistic capital at a disadvantage 
(Yosso, 2005). Lack of familial capital can add additional barriers to success for some ethnic groups. Families that have lived in the United States for multiple generations and have developed familial connections and experiences are at a distinct advantage when it comes to moving through the school system (Yosso, 2005).

Cultural capital (in all of its forms) is generally accumulated over generations and is an underlying force ensuring the status quo. In the American education system, cultural capital creates the illusion of equality while providing distinct advantages to the dominant culture (Bourdieu, 2011). The history of the country and the accumulation of cultural capital has contributed to the current disparities evident in American society and the school system. Social capital (a form of cultural capital) refers to the networks and connections that lead to relationships and membership with groups in the dominant culture. This adds to the advantages that some groups have historically had (and continue to have) over others both in American society and the American school system (Bourdieu, 2011).

Social reproduction theorists contend that the education system in America is doing exactly what it is designed to do, which is reproducing the status quo and preserving the dominant culture (even though this reproductive force can be unintentional) (Bowles \& Gintis, 2012). The disparities in achievement displayed previously confirm these theories as standardized test scores are used as a gateway to higher education in the American school system. The disparities in educational opportunities (coupled with a multitude of other factors) lead to disparities in student achievement outcomes, which in turn leads to further disparities in educational attainment. 
Race and racism. Issues of race and racism in America have existed since the beginning of this country and have yet to be fully addressed. These issues are both overt and covert and have a definite impact on the educational experiences for Black and Latino students. It is clear that issues of race and racism in the United States are indeed permanent social conditions because they are ongoing components of the social fabric of the country. Public schools are frequently crossroads of racially related tensions and are about the last institution where children and families of different wealth, ethnicity, and cultural values come together (Berliner \& Glass, 2014). With that said, racial issues are rarely discussed in American society and race is considered an "elephant in the parlor" topic. The racial achievement gap in the United States is unlikely to be reduced unless communities engage in thoughtful conversations about race (Singleton \& Litton, 2006).

Communities that have been able to openly discuss how students of different races experience teaching and learning in public forums have been able to reduce their racial achievement gaps (Singleton \& Litton, 2006). Being able to organize community members together to discuss, brainstorm, and explore multiple points of view on complex issues (like race) would generate new and better policy options (Gerzon, 2006). Part of the key to successfully facilitating a community conversation about race lies in the facilitator's ability to establish common language around race. Developing and using common language in conversations about race helps establish critical understandings around how racial issues impact schooling (Singleton \& Linton, 2006). These common understandings have simply not been developed in the majority of American school communities. Topics of race and class are simply avoided by the majority of Americans 
(including educators and educational leaders). This lack of consideration becomes a definite contributing factor that leads to the disparate outcomes between ethnicities that are being observed in American schools.

One topic that can definitely be considered an "elephant in the parlor" topic, in that it is rarely discussed or acknowledged (in schools or society), is the notion of white privilege. White privilege is the unearned advantages and assets experienced by people with white skin (McIntosh, 1988). White privilege has been described as an invisible package of "special provisions, maps, passports, codebooks, visas, clothes, tools, and blank checks" that contribute to the myth of meritocracy in America and American schools (McIntosh, 1988). White privilege is another one of the factors present in schools contributing to the disparate academic outcomes between various student populations that researchers continue to observe. White privilege is particularly challenging to address because most whites are unconscious of it and have been trained throughout their lives to remain oblivious to it (McIntosh, 1988).

Institutional isomorphism maintaining the status quo. Some scholars contend that the education system in America is doing exactly what it is designed to do, which is reproduce the status quo and preserve the dominant culture. The disparities in achievement discussed previously confirm these theories as standardized test scores are used as a gateway to higher education in the American school system. The disparities in student achievement between subgroups eventually leads to disparities in opportunities for students, and disparities in access to higher education.

The meritocratic perspective on American society likes to think of schools as a fair 
system where students can reach their potential, fulfill their aspirations, and seize the multitude of opportunities this country has to offer. While this idealistic scenario may be the case at times, more often than not the school system is a vehicle to ensure that (regardless of intent to the contrary) status quo is maintained and that the hierarchical social structure of the country remains undisturbed. The educational reform movements that have taken place in the United States have leaned on the "failing schools" rhetoric to ensure that the system continues to do what it was designed to do (maintain the structure of society).

Within the system, the way teachers and school systems work with students varies depending on the social class status of the student population. Social class is not always the same as the income level of the family, but it is often related. The hidden curriculum, or the way that students from different social classes are taught, is another way that schools (intentionally or not) ensure the status quo (Anyon, 1980). Students from lower classes are taught basic skills and compliant behaviors, where middle class schools focus on creativity and critical thinking. Students from lower classes often do not see themselves going to college, while students from middle class backgrounds hold the belief that if they work hard they can indeed attend college. Schools that serve upper class families focus on competitive academics and often desire to attend the most elite colleges and universities in the United States (Anyon, 1980).

Hidden curriculum refers to all of the subtle messages that students of different backgrounds are given throughout their schooling. This includes messages to students about what they can and cannot strive to become, the types of questions that they are 
asked, and how their teachers view them. The truth is that all students deserve access to enrichment opportunities and deserve to be taught the hidden curriculum that will enable them to have as good of a chance to be part of the upper class as anybody else.

Additional forces at play that lead towards maintenance of the status quo in American education include organizational behaviors and processes. Researchers that have studied organizational behaviors and processes refer to an "iron cage" to explain the lack of innovation that is so commonplace in many organizations (DiMaggio \& Powell, 2000). There are a multitude of factors that ensure status quo in many organizations and society in general. As much as individuals (and even groups) may try and promote changes in organizations there are powerful "isomorphic processes" or forces that lead all organizations to become increasingly similar, all of which are barriers towards significant improvements in organizations (such as school districts) (DiMaggio \& Powell, 2000). Coercive processes force organizations that are dependent on each other to adopt similar structures, procedures, and norms. Simultaneously, mimetic processes are rooted in the principal that organizations try and model themselves after other organizations that they perceive to be successful. Normative processes are rooted in professionalism and the similarities in education and experiences that the leaders of organizations all share (DiMaggio \& Powell, 2000). To compound the challenges, leaders who make it to the top of organizations (such as school districts) are virtually indistinguishable because they all attend similar institutions with similar training. Even when leaders from different backgrounds do emerge, they are put through a socialization process by their institution to think like the norm. These factors make institutional change incredibly challenging. 
Summary of factors affecting educational outcomes. The challenges and factors contributing to the inequitable outcomes in the education system are plentiful, complex, and extensive. Undoing or reversing hundreds of years of systematic oppression cannot be done overnight and requires committed, skilled, and motivated leadership.

Understanding the historical, political, and financial context of these achievement factors, as well as the varying and complicated interactions among factors that contribute to it will indeed assist with the undertaking of the challenge that is producing more equitable outcomes for underserved student populations. 


\section{Chapter 3}

\section{Methodology}

Achieving more equitable educational outcomes for students of color and economically disadvantaged students has always been a challenging task. This study examines OSD's desired journey towards reducing the disparities in educational outcomes and achieving more equitable outcomes for its students. This chapter provides details about the researcher as well as explains the methodology behind the study.

\section{About the Researcher}

My earliest memories coincide with my family's move from San Jose, CA to a farmcottage in Los Altos Hills, CA. You might think it funny to refer to a home in Los Altos Hills as a farm-cottage, but that is exactly what it was. My family moved when I was 5 years old (during the winter of 1985), well before the dot-com boom that made Los Altos Hills one of the wealthiest zip codes in the United States. Back in 1985, Los Altos Hills was mostly open fields of rolling hills and apricot orchards. I remember walking through the tall mustard grass with my brother. The grass was taller than us and we had to carve paths through it to get from place to place. The only rule my mother had for us was to be back before dark. The only real dangers we faced were rattlesnakes and mountain lions.

Even though the outdoor free time at home was quite fun and exciting, there was another element to it that was very challenging. My father essentially forced my brother and me to do massive amounts of manual labor. Most of our free hours were spent in manual labor. For a ten-year stretch through middle school, my brother and I essentially landscaped and leveled the entire back yard. My father would force us to shovel dirt into 
a wheelbarrow on one side of the yard and move it to the other side of the yard in an effort to level my parents' land. Hour after hour and day after day we were forced to do this menial task until we were finally old enough to physically stand up to him and tell him that we would not do it anymore.

The manual labor was incredibly hard, but there were positive side effects. The incredible work ethic that I have developed today is because of that work. The fact that I can endure almost anything and have the confidence that no amount of work is too difficult came from those years of manual labor. I also have an appreciation for the physically easy work that I do today. I have a real respect for those that actually have to toil in manual labor jobs to make a living. They are the ones that actually work for a living.

Sadly, the fields and orchards no longer exist in Los Altos Hills, CA. They have been replaced with mega-mansions protected by metal gates and surrounded by landscaped gardens. My parents still live in the same house, in the same condition, on the same 2acre plot now surrounded by mega-mansions and metal fences.

My parents are Iranian immigrants and my mother claims that I could not speak English when I entered Kindergarten. I must have learned fast, because I have no memories of being frustrated from not being able to communicate with teachers or classmates. From my experience as an educator working with English Language Learners, I now know that it is quite common for young students to rapidly pick up the English language. 
I do remember that my school community was very homogeneously white and that I was the one of the very few students of color in the entire school. I felt different. My culture was different and I looked different. I was constantly reminded that I was different. Those around me in school made sure to remind me of this all the time. Because of this, I often pushed back and rejected my schooling and frequently underachieved because I correlated academic achievement with "acting white" (Valenzuela, 1999). It was a painful feeling and it was this pain that drove me towards a career in education. I have dedicated my career to those students that feel the pain of being ostracized (whether it is because of the way they look or their parents' income) every day.

I have talked to my younger siblings about their school experiences and while they felt a lot of the same pain, I do not think that it was nearly as dramatic as it was for me. My little sister is 12 years younger than me and the school demographics by the time she enrolled in kindergarten were a lot more diverse. My siblings got to be around kids from a variety of cultural backgrounds and there were many kids that looked like them in the neighborhood schools we attended.

I remember that holidays were particularly difficult for me, especially Christmas. I remember my classmates talking about their Christmas trees and all of the presents they were getting. We did not celebrate Christmas. We did have a family holiday tradition however (I did not like it at the time but, I am very proud of it now). Every year, during winter break, my family would pack up our mini-van with all the clothes that we had outgrown and all of the toys that we had lost interest in. We even gathered things from 
other families that we knew. When we finished packing up the mini-van, we headed south on a road trip to Mexico. When we crossed the border, we stopped at orphanages and small (impoverished) villages. We opened up the back of the mini-van and handed our belongings to the children and families that gathered around the car.

Even though I didn't love the yearly winter ritual at the time, reflecting back on the experience I now realize that those trips gave me a worldly view and a true appreciation for the things I did have in my life. Those trips shaped me into the person that I am today. Being the child of an immigrant family, growing up in a community that didn't really value diversity was tough. The yearly trips to Mexico gave me an awareness of my privilege. The challenges I faced growing up were minimal compared to those of the students that I have dedicated my career to. I never once had to worry about feeling safe in my neighborhood, a meal, or access to a warm bed to sleep in at night.

The most painful memory of my elementary school experience had to do with my relationship with my next-door neighbor. Across the field, behind my house, lived a boy named Jason. He was my age and in my grade in school. It was only a two-strand school and many years we were even in the same class. We played together almost every day (in the field that connected our backyards). At school it was completely different. Most of the time he ignored me, pretending that I didn't exist. That was when he was being nice. Some of the time he joined other students in making fun of the food I ate, the way I looked, and the way I smelled. To this day, I do not understand why he treated me this way. It must not have been cool to be my friend. 
The one area that brought me the most joy growing up was athletics. It was the one place in the school-community where I felt equal to my peers. It was the place where it didn't matter what I looked like, what I ate, or how I smelled. It was my safe place. From kindergarten to the day I graduated high school, the only thing I did during recess or lunch was play pickup basketball, soccer, baseball, or football in the yard. Sports continued to be a very important aspect of my life all the way through college and to this day. Most of my life-long friends were my teammates on recreational league teams growing up, the high school teams I played on, my college rugby team, and my club rugby team after college. The bonds that I developed with people through athletics will last the rest of my life.

While I did very well in athletics, academics were not easy for me. I was simply not that interested in most of the things that my teachers wanted to teach me. Honestly, the only reason I even graduated high school was the fear of my parents and wanting to stay eligible to compete on the football, wrestling, and rugby teams.

Even though I was not very big in stature, (only 98 pounds when I entered 9th grade), I think I was drawn to the more violent sports like football, wrestling, and rugby because they provided an outlet for the frustrations I was feeling in the classrooms. Early on, I became aware of and resentful of the unfair advantages some of my classmates were getting because of their cultural capital.

Being immigrants, my parents did not understand the educational system enough to advocate for me like the parents of many of my classmates did. My family was deficient in the navigational capital needed to effectively manipulate the school system on my 
behalf (Yosso, 2005). In a lot of ways, I was essentially on my own. I remember I would get a poor grade on a quiz or a test, but my score was still better than many of my classmates. I also remember that many kids were actually able to get their quiz scores changed or get the chance to take the quiz again because their parents would lobby for them with their teachers.

There was nobody making excuses for me or lobbying and advocating on my behalf. Even if my mother wanted to, she couldn't speak English well enough to articulate a coherent argument. What she lacked was the linguistic capital needed to advocate for me like the parents of many of my peers did (Yosso, 2005). Even if she could lobby on my behalf, I doubt she would have because it was not in our culture to make excuses for poor performance. The expectation was that we would accept responsibility for our choices and failures. I remembered this and made sure it was a disadvantage that my younger siblings would not have to deal with. Knowing the system, I advised them and advocated for them as if I was their parent and they had much more academic success than I did. I was aware that being the oldest child of an immigrant family carried additional challenges and responsibilities, and I wanted to reduce the additional challenges that my siblings had to overcome.

Besides lobbying for grades, another way that the parents of my classmates would lobby for their kids was by making sure that their children would get the better teachers and more importantly, the teachers that were easier graders. This is another way that I would advocate for my siblings, as I would look over their schedules and make sure that they got the right teachers who would ensure their success. In this sense, my siblings had 
more familial capital than I did being the first-born child in the family (Yosso, 2005). After all, that is what many other students were doing. We may not have had cultural capital at first, but we got it eventually. Such is the immigrant experience for many, I suppose. When I became an educator, I became hyper-aware of the inherent injustices in the system and I have fought against them at every turn. I will continue to be the voice for the voiceless and an advocate for those that do not have one.

Since I was far from an exemplary student in high school and college was not an option for me (though my parents said I had to go), I ended up at the local junior college. It was there that I finally started to show some interest in some academic areas. The classes that really spoke to me were in the fields of U.S. history and political science. My teachers in junior college inspired me with stories of injustice and those that fought against it. I went on to transfer to the UC system and majored in political science with a minor in US history. The more choice I got over what I was studying, the more interested in academics I became.

After receiving my undergraduate degree, my passion for learning was still burning. I ended up earning master's degree in education and a second master's degree in educational administration. Not bad for a kid that didn't really like school. I now consider myself a lifelong learner and I want to be an example for all the kids out there that do not believe that an education is of value.

As a first generation American and English language learner, I faced many challenges while going through the school system. I was aware of the advantages some of my peers had over me. I was also aware of the inequities some students (including myself) dealt 
with on a daily basis. As I began to decide on a career, I was drawn towards education as I felt that I could make a difference supporting students that we have historically underserved as a society. Equity issues were at the core of my professional work as I taught in the classroom and served as an English Language Development teacher, an instructional coach (in OSD), and a district administrator in a new district.

I have spent my entire career asking questions about the best ways to serve all of our student populations and trying to figure out why the disparities in academic outcomes were so prevalent, and why it was so challenging to reduce the inequities in the school system. I was a member of Ocotillo's Minority Achievement and Talent Development Committee (MATD) and was part of the team that conducted the research and made the equity recommendations to the district. Now that I have left Ocotillo, I am interested in better understanding the impact and legacy of the MATD recommendations. While making the equity-minded recommendations, we always felt that if the goal of reducing disparities in educational outcomes can be achieved anywhere it could and should happen in OSD. My hope is that this study can provide valuable insights for other districts trying to attain the same goals as Ocotillo and that they can learn from both the successes and remaining challenges for the district.

\section{Restatement of the Purpose of the Study}

This dissertation is a case study of Ocotillo's efforts to achieve more equitable educational outcomes for its Black, Latino, and economically disadvantaged students. The research questions addressed by this study are as follows: 
1. What progress has been made towards the MATD Committee's goals since its recommendations in 2015 ?

2. What are teacher/school administrator knowledge, beliefs, and attitudes towards equity issues in education (generally) and at OSD specifically?

3. What factors do school site administrators and teachers say they have to manage when implementing initiatives aimed at reducing disparities in educational outcomes among their students?

4. Has the district initiative to reduce disparities in educational outcomes changed the way that teachers/school administrators operationalize and reflect on their practice? If so, how?

In order to report findings about the successes and remaining challenges faced by OSD on their desired journey towards more equitable educational outcomes for its students, I have decided to utilize case study research methods (Stake, 1995). My case study will examine different perspectives from across the district in an attempt to gather and present information, insights, and to tell the OSD story as it pertains to the research questions above. Figure 2 outlines the approach for data collection in this study.

\begin{tabular}{|c|c|}
\hline $\begin{array}{cl}\text { Progress Towards MATD Committee Goals } \\
\text { - } & \text { Disaggregated SBAC scores by } \\
& \text { Ethnicity } \\
\text { - } & \text { Disaggregated SBAC scores by SES } \\
\text { - } & \text { Additional MATD success indicators } \\
\end{array}$ & $\begin{array}{c}\text { Ocotillo Teacher Perspectives } \\
\text { - } \text { K-2 Grade Teachers } \\
\text { - } 3-5 \text { Grade Teachers } \\
\text { - } \quad \text { 6-8 Grade Teacher }\end{array}$ \\
\hline $\begin{array}{c}\text { Ocotillo Site Administrator Perspectives } \\
\text { - } \quad \text { One elementary school principal } \\
\text { - } \quad \text { One middle school dean } \\
\end{array}$ & $\frac{\text { Ocotillo District Office Perspective }}{\text { - District Administrator }}$ \\
\hline
\end{tabular}

Figure 2. Four-part case study approach.

Because of the resources available, the diverse community, and its history of equity issues, OSD offers a unique opportunity to see how some strategies for reducing educational inequities work in an affluent school setting. The focus of this study will be 
on how the district equity initiatives are received and implemented at the elementary school and middle school levels. Even though Ocotillo is a K-12 district, I chose to focus this study on the elementary and middle school grades, as educational outcomes are often predictable before a student steps foot on a high school campus.

For this study, I interviewed teachers and administrators from four elementary schools (two schools from the northern side of the district and two from the southern side) and one middle school from the southern side of the district. The study also includes classroom observations and site visits to gather artifacts to better understand the successes and remaining challenges for OSD as they continue on their desired journey towards more equitable outcomes. After the initial interviews and classroom observations/site visits, I scheduled follow up interviews with the teacher participants for further questioning about the observation notes and artifacts collected.

In my analysis, I reviewed the recommendations and goals of the MATD Task Force as well as the results from state testing data for OSD. My research questions were addressed by using the interview transcripts from the elementary school teachers, middle school teacher, and administrators that participated in my study. I analyzed the observation notes and artifacts collected from my site visits to inform my research questions. The interview protocol below included the questions that I asked during the initial interviews and the correlation to my research questions. 


\section{Interview Protocol}

I conducted interviews with one district level administrator, teachers and site administrators from four elementary schools and one middle school and asked the following questions:

1. What does equity in education mean to you? (RQ-2)

2. What does equity look like at your school/in your classroom? (RQ-2)

3. What are some challenges that you face when trying to promote equity in your school/classroom? (RQ-3)

4. What do you know about the MATD initiatives and have they impacted your practice? (RQ-4)

5. How have your beliefs about equity changed over the course of your career? Or over the last couple years? (RQ-4)

6. What are practices you use to promote equity? (RQ-2 and RQ-3)

My follow up interviews (and questions) depended on the observation notes and artifacts collected from my site visits.

\section{Participants}

To recruit interview subjects I sent a short survey and invitation to all teachers and the site administrators at the four elementary schools and one middle school that I selected for my study. Participation in the study was voluntary and the email invitation/survey stated that the district's research department had granted permission to conduct the study. The email invitation included the following message:

My name is Arcia Dorosti and I am conducting a study on equity issues in education and the MATD Committee's efforts to reduce the disparities in educational outcomes between economically disadvantaged students and more affluent students as well as

the disparities in educational outcomes between students of color and White and 
Asian students. I am doing this research with the hopes that other districts can learn from the successes of OSD and the challenges that remain for the district.

All of the interview participants in my study were asked to sign consent forms agreeing to participate in the study.

I interviewed ten elementary and middle school teachers, a site administrator from one elementary school and one middle school, as well as an administrator from the district office. I selected participants to balance the number of teachers from each of the school sites that I selected and picked teachers working in a variety of grade levels and roles. I also looked to balance the number of participants that work in both the northern and southern sides of the city and I looked for a balance of participants with a variety of experience levels. Table 5 shows the participants selected, the geographic balance of the participants, as well as the balance of roles of the participants in the study. 
Table 5

Participant Matrix

\begin{tabular}{|l|l|l|l|l|l|l|}
\hline School & Townsend & Barkley & Johnson & $\begin{array}{l}\text { Prairie } \\
\text { View }\end{array}$ & Austin & $\begin{array}{l}\text { District } \\
\text { Office }\end{array}$ \\
\hline K-2 Teachers & & Toni & Elaine & & Alice & \\
\hline 3-5 Teachers & & Sally & Lacy & Jane & & \\
\hline $\begin{array}{l}\text { 6-8 Teachers } \\
\text { (MS) }\end{array}$ & Tracy & & & & & \\
\hline Specialists & & $\begin{array}{l}\text { Ann \& } \\
\text { Cindy* }\end{array}$ & & Avery & & \\
\hline Administrators & Larry & & & & Ally & Corey \\
\hline
\end{tabular}

\begin{tabular}{|l|l|}
\hline$*$ & Works at Multiple Elementary Sites \\
\hline & South Ocotillo Schools \\
\hline & North Ocotillo Schools \\
\hline
\end{tabular}

Before I began interviewing participants for the study, I tested my interview questions with trusted colleagues and classmates to see if the questions I was asking would elicit the types of responses that I needed to inform the study. From these test trials I was able to adjust the wording of my questions to maximize the relevant information that I would be getting from the interview participants, as well as confirm the validity the interview protocol as a data collection tool.

I conducted all of my interviews in person and taped and transcribed the interviews. I reviewed the interview transcripts later for analysis. My interview participants did not include teachers or administrators who served on the MATD Committee, but did include teachers that are in specialist roles such as reading specialists, librarians, and speech and language pathologists. I did not report the identity of the participants in the study and only referred to the participants by their general position in the organization and using 
pseudonyms. The names of the schools that participated in the study are also

pseudonyms. Table 6 provides general information about each of the participants

including their specific positions and years of experience.

\section{Table 6}

Participant Information Table

\begin{tabular}{|c|c|c|c|}
\hline Name & Position & Years of Experience & Background \\
\hline \multicolumn{4}{|c|}{ Townsend Middle School } \\
\hline Tracy & $\begin{array}{l}6^{\text {th }} \text { Grade Social Studies } \\
\text { Teacher }\end{array}$ & 9 years & Has been in current position and site for entire career. \\
\hline Larry & Middle School Dean & 23 years & $\begin{array}{l}\text { Has taught in multiple districts, elementary school and } \\
\text { middle school teaching experience. } \\
\text { First year administrator. }\end{array}$ \\
\hline \multicolumn{4}{|c|}{ Barkley Elementary School } \\
\hline Toni & Kindergarten Teacher & $20+$ years & $\begin{array}{l}\text { Has taught at multiple sites within district and at } \\
\text { multiple elementary grade levels. }\end{array}$ \\
\hline Sally & $4^{\text {th }}$ Grade Teacher & 12 years & Entered teaching profession after career as a scientist. \\
\hline Ann & Reading Specialist & 10 years & $\begin{array}{l}\text { Has taught in multiple districts and multiple elementary } \\
\text { grade levels, worked in district office as an instructional } \\
\text { coach. } \\
\text { Second year Reading Specialist. }\end{array}$ \\
\hline Cindy & Speech Language Pathologist & 9 years & $\begin{array}{l}\text { Splits time between two elementary school sites within } \\
\text { district. }\end{array}$ \\
\hline \multicolumn{4}{|c|}{ Johnson Elementary School } \\
\hline Elaine & $1^{\text {st }}$ Grade Teacher & 6 years & $\begin{array}{l}\text { Has taught in multiple districts and elementary grade } \\
\text { levels. }\end{array}$ \\
\hline Lacy & $3^{\text {rd }}$ Grade Teacher & 13 years & $\begin{array}{l}\text { Has taught in multiple districts and multiple elementary } \\
\text { grade levels, worked in district office and county office. }\end{array}$ \\
\hline \multicolumn{4}{|c|}{ Prairie View Elementary School } \\
\hline Jane & $5^{\text {th }}$ Grade Teacher & 15 years & $\begin{array}{l}\text { Has taught at multiple sites within district and at } \\
\text { multiple elementary grade levels. }\end{array}$ \\
\hline Avery & Librarian & 23 years & $\begin{array}{l}\text { Has worked at multiple sites within district and has } \\
\text { experience as a classroom teacher. }\end{array}$ \\
\hline \multicolumn{4}{|c|}{ Austin Elementary School } \\
\hline Alice & $2^{\text {nd }}$ Grade Teacher & 21 years & Has taught at multiple elementary grade levels. \\
\hline Ally & Principal & 19 years & $\begin{array}{l}\text { Has worked for multiple districts and has experience as } \\
\text { a classroom teacher and an instructional coach. }\end{array}$ \\
\hline \multicolumn{4}{|c|}{ District Office } \\
\hline Corey & Director & 22 years & Has worked in multiple states as an administrator. \\
\hline
\end{tabular}

To build rapport with the participants and to provide general information about the study, I shared Figure 3 with each participant before each initial interview session began. 


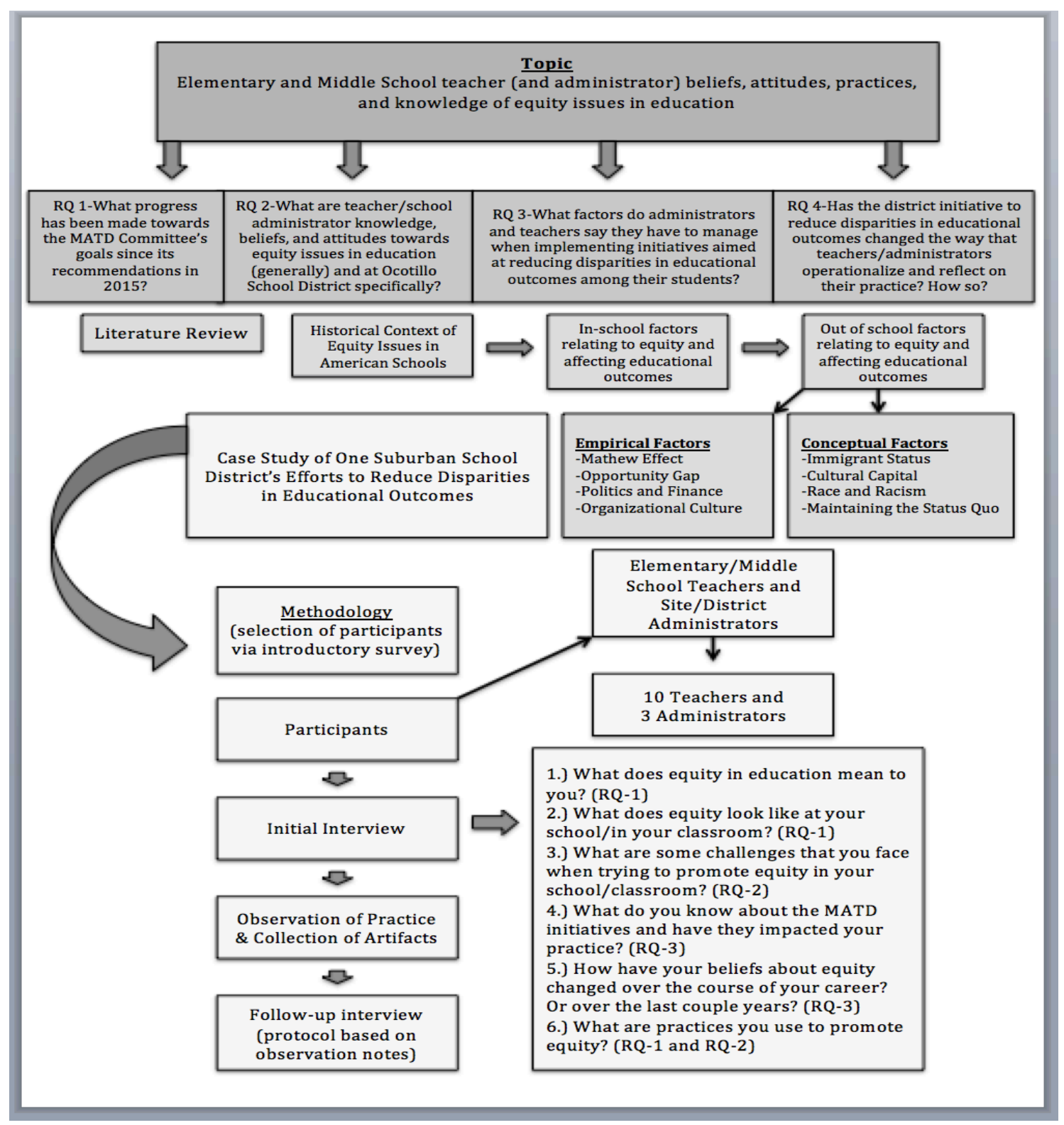

Figure 3. The figure was used to explain the dissertation topic and provide background information to participants.

Sharing Figure 3 allowed participants to have a better understanding of the purpose of the study, as well as a preview of the questions that I was going to ask them. Re-iterating the purpose of the study helped reduce any anxiety the participants may have had, while the preview of the questions helped the participants provide more thorough responses. 


\section{Data Analysis}

I analyzed the interview transcripts by coding the data to look for trends and themes relating to equity and educational outcomes. As I reviewed the transcript data, I focused on attitudes of the participants as they related to organizational change efforts. Equity efforts in a school district the size of Ocotillo are often tied to the attitudes of the teachers and administrators asked to carry out the initiatives and dependent on the ability of the organization to change its culture (to become more equity minded) (Auster \& Ruebottom, 2013). Cultural change in an organization is often a difficult and slow process (as cited in the literature review).

\section{Coding}

I reviewed interview transcripts from my initial interview as well as the second interview that I conducted with the teacher-participants after observing them in the classroom. During the classroom observations, I took notes about practices that I was observing. In my follow up interview with teachers, I referred to my notes to ask questions that would help me better understand practices being used that could potentially be related to positive educational outcomes for students. I also collected artifacts from each of the participants in the form of agendas from various staff meetings and department meetings from across the district.

I coded all of the transcripts, my classroom observation notes, and the agendas that I collected to look for connections to the original 12 MATD Task Force recommendations. I did this by highlighting any mention of any part of the MATD Task Force recommendations. I also highlighted any mention of practices or strategies related to 
producing more equitable outcomes in schools. To be more specific, I coded the documents with two main lenses. As I read through the documents, I highlighted anything mentioned relating to in-school practices from my literature review (or otherwise) in yellow. I then proceeded to read the documents again and coded the participant responses as they related to my research questions. I highlighted any part of any response that related to research question $\# 2$ in pink, any part of any response relating to research question \#3 in blue, and any part of any response relating to research question \#4 in green. In the analysis, I will discuss my findings in terms of my four research questions and I will highlight both the successes and remaining challenges for the district as described in the documents that I collected.

\section{Limitations}

This study had several limitations. The first limitation being that organizational change efforts take lots of time and are difficult to quantify. Another limitation pertains to the historical insensitivity of standardized test data regardless of any initiatives within an organization. Since there is such a strong correlation between standardized test scores and out-of-school factors, changes in state standardized test data are unlikely to be found in a short period of time. It has only been three years since the initiatives have been introduced to the district and all of the recommendations of the MATD Committee have yet to be fully implemented. This study only focuses on the early stages of implementation of the initiative and the successes and challenges encountered in the first three years of implementation. 
Another limitation is that I am a former employee of the school district in the case study, as well as a former member of the MATD Committee. The fact that I served on the committee and used to be employed by the district may have had an impact on the interview responses. Teachers and administrators may have responded with what they think I wanted to hear or may have been worried about the connections I have within the district and may not have been fully open with their responses. Of course, the opposite may also have been true and my relationship with the interview subjects may have lead to more open responses from the participants and I may have been able to get more information than a true outside researcher would have been able to get. I addressed these limitations by establishing rapport with the interview subjects and assuring them that their identity will be protected and that what they shared would not be disclosed to their supervisor or any other high-ranking district official.

In addition to initial interviews, I checked the interview responses of the participants against observation notes from site/classroom visits. I made sure to reiterate that the purpose of my study was to learn from the successes and remaining challenges facing OSD in an effort to help other districts on their desired journeys towards more equitable academic outcomes for their students. 


\section{Chapter 4}

\section{Findings}

In this chapter, I will discuss my findings as they relate to each of the research questions outlined in Chapter 1. The excerpts from the interview transcripts that I include in this chapter are the words of the participants. I took minor liberties when including excerpts from transcripts including cleaning up the grammatical construction of sentences, adding punctuation when needed, and inserting ellipses when excerpts got too long or went off topic. I also collected artifacts from all of my participants in the form of agendas from various staff meetings or department meetings from across the school district.

I spent approximately four months interviewing, observing, and collecting artifacts from thirteen OSD employees. All of the participants responded to my survey expressing interest in being included in my study, and I selected each of them to create a balance of perspectives of employees in a variety of roles across the district. The participants included seven classroom teachers, three teachers in support roles (a speech language pathologist, a reading specialist, and a librarian), and three administrators (an elementary principal, a middle school dean, and a district office director). I interviewed a teacher from each grade level (kindergarten through the sixth grade) and for each teacher interview I returned for an observation of a lesson, and conducted a second interview with the teacher, asking questions about my observations. The interviews, observation notes, and artifacts I collected created a triangulation of data sources leading to more 
reliable findings. From the time I spent gathering data from my participants, I was able to develop insights informing each of my research questions.

\section{Ocotillo SBAC Results 2015-2017 and Research Question \#1}

As I begin a discussion of my findings, as they relate to my research questions, I will discuss OSD's disaggregated results from state (SBAC) testing. The MATD Task Force stated seven indicators (all seven indicators are included in Chapter 1) that the district will be using to evaluate the success of its equity initiative. Research question \#1 asks, "What progress has been made towards the MATD Committee's goals since its recommendations in 2015?" Two of the seven MATD Committee indicators relate directly to state testing. The MATD Committee stated that two of the ways that they will be evaluating the effectiveness of the implementation of their equity initiative is by looking for "an increase in the percentage of under-resourced and minority students at or above state benchmarks in reading and math" and "a reduction of under-resourced and minority students below proficient in statewide assessments."

Since SBAC test data is public, I have used the state website displaying assessment results to create the following table. Table 7 illustrates the extent to which the district has made progress towards its stated goals around state testing. 
Table 7

OSD Three-Year Smarter Balanced Assessment Consortium Disaggregated Results

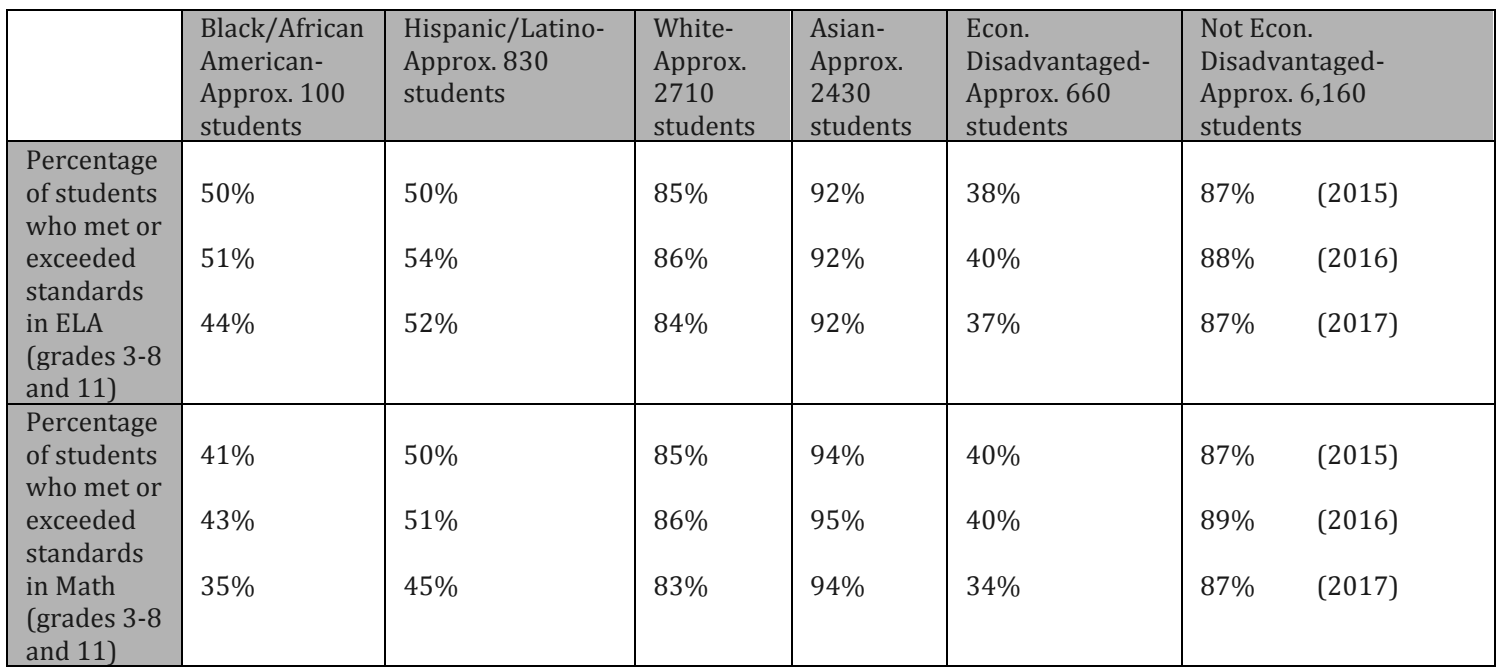

Note: Table adapted from California Department of Education, 2017

Table 8 shows that in the first three years of MATD Committee implementation, there has been very little to no progress made towards the Committee's stated goals of "an increase in the percentage of under-resourced and minority students at or above state benchmarks in reading and math," and "a reduction of under-resourced and minority students below proficient in statewide assessments." In fact, the overall disparities in educational outcomes for underserved students in OSD (according to the state assessment data) have generally increased during the last three years. These findings indicated that student SBAC scores (for underserved student populations in OSD) in English Language Arts and Mathematics on California's standardized tests have not improved over three years $(2015,2016$, and 2017).

\section{Ocotillo School District enrollment in Advanced Placement courses. OSD} provided data (from 2015, 2016, and 2017) on the number of students in Advanced 
Placement courses at the two high schools (disaggregated by ethnicity). Between the two high schools in OSD, there are approximately 6,000 available seats in various Advanced Placement courses offered each year. Table 8 shows the number of those seats (each year) taken by African-American and Hispanic/Latino students.

Table 8

OSD Three-Year Advanced Placement Enrollment By Ethnicity

\begin{tabular}{|l|l|l|}
\hline $\mathbf{2 0 1 5}$ & $\mathbf{2 0 1 6}$ & $\mathbf{2 0 1 7}$ \\
\hline $\begin{array}{l}\text { Number of Total Seats in } \\
\text { Advanced Placement } \\
\text { Courses-5972 }\end{array}$ & $\begin{array}{l}\text { Number of Total Seats in } \\
\text { Advanced Placement } \\
\text { Courses-6410 }\end{array}$ & $\begin{array}{l}\text { Number of Total Seats in Advanced } \\
\text { Placement Courses-6338 }\end{array}$ \\
\hline $\begin{array}{l}\text { Number of Advanced } \\
\text { Placement Seats Taken by } \\
\text { African-American Students- } \\
18(0.3 \%)\end{array}$ & $\begin{array}{l}\text { Number of Advanced } \\
\text { Placement Seats Taken by } \\
\text { African-American Students- } \\
36(0.5 \%)\end{array}$ & $\begin{array}{l}\text { Number of Advanced Placement Seats } \\
\text { Taken by African-American Students- } \\
61 \text { (1\%) }\end{array}$ \\
\hline $\begin{array}{l}\text { Number of Advanced } \\
\text { Placement Seats Taken by } \\
\text { Hispanic/Latino Students-347 } \\
(6 \%)\end{array}$ & $\begin{array}{l}\text { Number of Advanced } \\
\text { Placement Seats Taken by } \\
\text { Hispanic/Latino Students-155 } \\
(2 \%)\end{array}$ & $\begin{array}{l}\text { Number of Advanced Placement Seats } \\
\text { Taken by Hispanic/Latino Students- } \\
234 \text { (4\%) }\end{array}$ \\
\hline
\end{tabular}

Table 8 shows that there has been a steady increase in the number of AfricanAmerican students enrolled in Advanced Placement Courses from 2015-2017, indicating that some progress has been made towards the MATD Task Force's goal of "increasing the percentage of under-resourced and minority students taking advanced level courses in high school." The numbers for Hispanic/Latino students are more varied and show fluctuation between 2015-2017. To put these numbers in context, it is important to remember that Hispanic/Latino students represent about $11 \%$ of the total OSD population 
and African-American students represent approximately $2 \%$ of the total OSD population. It is also important to note that the remaining seats in Advanced Placement courses that were not filled by African-American or Hispanic/Latino students were filled by White, Asian, or multi-racial students.

Ocotillo School District graduation rates. The California School Dashboard (the state's new school accountability system) reports high school graduation rates to the public. Increasing high school graduation rates for historically underserved student populations is another one of the MATD Task Force's success indicators. According to the California School Dashboard, OSD has a very high comparative graduation rate for all of its students with $95.1 \%$ graduating in 2017 (with the percentage increasing by 0.02\% from 2016). For OSD's African-American students, the California School Dashboard reports a high graduation rate with $90.6 \%$ graduating in 2017 and an overall improvement of $2.3 \%$ from 2016 . However, socio-economically disadvantaged students and Hispanic/Latino students in OSD are not showing the same progress in graduation rates as African-American students. According to the California School Dashboard, OSD graduates a comparatively low percentage of its socio-economically disadvantaged students with only $80.7 \%$ graduation rate in 2017 and that number declined by $6.1 \%$ from 2016. For OSD's Hispanic/Latino students, the California School Dashboard reports a medium graduation rate of $86.5 \%$ in 2017 , but the percentage declined by $6.7 \%$ since 2016. Though there was some progress in graduation rates for OSD's African-American students, the positive results do not carry over to Hispanic/Latino students or socioeconomically disadvantaged students. 
The MATD Task Force goals also included a desire to, "increase participation in mainstream clubs and student government for under-resourced and minority students." Data on this metric was not offered by OSD's Research Department and it is not public data. Therefore, my findings will not include a discussion of information on this metric.

Ocotillo School District suspension rates. The two remaining MATD Task Force goals that I have not yet discussed include, "a reduction of referrals of under-resourced and minority students to Alta Verde High School" (the alternative high school where expelled students are sent) and "growth of student connectedness for under-resourced and minority students on the California Healthy Kids Survey." While these data were not offered to me by OSD's Research Department, nor are they directly reported by the state, there are metrics from the California School Dashboard that can add insight into these goals.

A look at suspension rates offers insight into students that are expelled, as multiple suspensions in OSD lead to referrals to the alternative high school (Alta Verde High School). According to the California School Dashboard, OSD had a very low comparative overall suspension rate of $0.8 \%$ in 2017 , even though the overall suspension rate in OSD increased by $0.4 \%$ from 2016 . The Dashboard also reports that socioeconomically disadvantaged students in OSD had a comparatively low suspension rate of $2.3 \%$ in 2017 , which had increased by $0.9 \%$ from 2016 . For OSD's AfricanAmerican students, the California School Dashboard Reports a comparatively high suspension rate of $6.6 \%$ in 2017 , which had increased by $4.7 \%$ since 2016 . OSD's Hispanic/Latino students were reported by the California School Dashboard as having a 
comparatively low suspension rate of $1.1 \%$ in 2017 , which increased by $0.1 \%$ from 2016 . If suspension rate data is used as a method to measure OSD's progress towards its goal of "reducing the number of referrals to Alta Verde High School," then it can be concluded that some progress has been made for Hispanic/Latino students, but little to no progress has been made for African-American students or socioeconomically disadvantaged students. Compared to the overall suspension rates for the district (in 2017), AfricanAmerican student suspension rates are more than six times higher than the overall suspension rates for the district and they have increased dramatically from 2016 to 2017 . OSD's socioeconomically disadvantaged student suspension rates are more than twice as high as the overall suspension rates for the district, while also increasing from 20162017. On the other hand, Hispanic/Latino suspension rates in 2017 are similar to the overall rates for the district. Additionally, suspension rates for Hispanic/Latino student essentially stayed the same between 2016 and 2017.

Ocotillo School District chronic absenteeism. To evaluate OSD's goal of "growing student connectedness for under-resourced and minority students on the California Healthy Kids Survey," I looked at chronic absenteeism data for the district. The California Healthy Kids Survey data is not public and it was not provided to me by the district's Research Department. However, by studying the rates of chronic absenteeism for underserved student populations in OSD, some insight can be gained into student connectedness within the district. The California School Dashboard does provide the public with information on chronic absenteeism in the state's schools. According to the California School Dashboard, the chronic absenteeism rate for the state during the 2016- 
17 school year was $10.8 \%$, but for OSD the overall chronic absenteeism rate in 2016-17 was 5\%. The reported chronic absenteeism rates (during the 2016-17 school year) for OSD's African-American and Hispanic/Latino students were $10 \%$ and $8.7 \%$ respectively. This data shows that that there is still work to be done in the area of school connectedness for African-American and Hispanic/Latino students.

Progress towards implementation of MATD recommendations. Table 9 provides updated information regarding the original 12 recommendations from the MATD Committee.

Table 9

MATD Update on Original 12 Recommendations

\begin{tabular}{|l|l|}
\hline Recommendation & Progress \\
\hline $\begin{array}{l}\text { 1.) Identify and administer a Pre-K to 2nd } \\
\text { grade diagnostic literacy and mathematics } \\
\text { assessment and provide Tier I } \\
\text { interventions and ongoing monitoring and } \\
\text { intervention as necessary and assure that } \\
\text { administrators and faculty have ready } \\
\text { access to this data, review it regularly and } \\
\text { use it meaningfully. }\end{array}$ & $\begin{array}{l}\text { OSD has switched its K-5 reading } \\
\text { assessment system to the Benchmark } \\
\text { Assessment System (BAS), which has a } \\
\text { diagnostic component. In mathematics, } \\
\text { OSD has implemented the Northwest } \\
\text { Evaluation Association (NWEA) } \\
\text { diagnostic assessment for grades K-2. }\end{array}$ \\
\hline $\begin{array}{l}\text { 2.) Commission an independent audit of } \\
\text { current intervention programs to identify } \\
\text { the most cost-effective. }\end{array}$ & $\begin{array}{l}\text { The OSD Research Department has added } \\
\text { additional personnel responsible for } \\
\text { monitoring academic interventions across } \\
\text { the district. }\end{array}$ \\
\hline
\end{tabular}




\begin{tabular}{|l|l|}
\hline $\begin{array}{l}\text { 3.) Employ an Equity Coordinator to lead } \\
\text { the development of the Equity Plan and } \\
\text { serve as an ombudsperson for managing } \\
\text { issues related to the education and well } \\
\text { being of historically underrepresented } \\
\text { students and families. }\end{array}$ & $\begin{array}{l}\text { OSD has hired an Equity Coordinator } \\
\text { who developed a board approved Equity } \\
\text { Plan for the district. The Equity } \\
\text { Coordinator now leads all MATD } \\
\text { Committee meetings. }\end{array}$ \\
\hline $\begin{array}{l}\text { 4.) Launch California Teacher staff } \\
\text { development sessions on unconscious } \\
\text { bias, with equity trainings for all staff } \\
\text { every four to six years. }\end{array}$ & $\begin{array}{l}\text { All OSD employees have completed a } \\
\text { two-day training on unconscious bias. }\end{array}$ \\
\hline $\begin{array}{l}\text { 5.) Based on the results of the diagnostic } \\
\text { assessment for kindergarten students, } \\
\text { provide an additional two days a week of } \\
\text { extended or full-day kindergarten. }\end{array}$ & $\begin{array}{l}\text { Beginning in 2016, all Kindergarten } \\
\text { classes in OSD have implemented a full- } \\
\text { day schedule. }\end{array}$ \\
\hline $\begin{array}{l}\text { 6.) Ensure that extensive summer } \\
\text { enrichment and after-school programming } \\
\text { is available for historically } \\
\text { underrepresented students. }\end{array}$ & $\begin{array}{l}\text { In the summer of 2015, an enrichment } \\
\text { summer program specifically for } \\
\text { underserved student populations was } \\
\text { implemented serving approximately 600 } \\
\text { K-8 students. }\end{array}$ \\
\hline $\begin{array}{l}\text { 7.) Employ mathematics intervention } \\
\text { support personnel for middle schools. }\end{array}$ & $\begin{array}{l}\text { Middle school sites now use a co-teaching } \\
\text { structure in some classes reducing the } \\
\text { teacher to student ratio and provide math- } \\
\text { tutoring support after school. }\end{array}$ \\
\hline $\begin{array}{l}\text { 9.) Assure new hirings for teachers and } \\
\text { administrators are representative of our } \\
\text { district's diverse populations. }\end{array}$ & $\begin{array}{l}\text { Every school site in OSD now has a } \\
\text { classified employee serving as a Home- } \\
\text { School Liaison responsible for outreach } \\
\text { to underserved student populations. }\end{array}$ \\
\hline $\begin{array}{l}\text { 10.) Create a system for obtaining, } \\
\text { analyzing and reporting data necessary to } \\
\text { monitor progress and report on results. }\end{array}$ & $\begin{array}{l}\text { OSD sarent } \\
\text { for analyzing and reporting student data } \\
\text { to monitor student progress. }\end{array}$ \\
\hline
\end{tabular}




\begin{tabular}{|l|l|}
\hline $\begin{array}{l}\text { 11.) Strengthen existing community } \\
\text { partnerships and foster new ones to } \\
\text { encourage innovative supports and } \\
\text { enrichment for underrepresented students. }\end{array}$ & Progress limited or unknown \\
\hline $\begin{array}{l}\text { 12.) Create clear, objective, and well- } \\
\text { communicated information about laning } \\
\text { decisions and waivers in mathematics in } \\
\text { middle school and high school. }\end{array}$ & $\begin{array}{l}\text { Waiver systems for middle school math } \\
\text { classes have been implemented and } \\
\text { information about the waiver process has } \\
\text { been clarified and translated to multiple } \\
\text { languages. }\end{array}$ \\
\hline
\end{tabular}

Table 9 shows that significant progress has been made towards the implementation of the initial 12 MATD Task Force recommendations. The shaded boxes (Nos. 4,5, and 8) note recommendations that were discussed during interviews with participants. Time will tell if the MATD initiative will eventually translate into sustained improved educational outcomes for OSD students, and after three years progress towards the MATD Committee's success indicators is mixed.

\section{Research Question \#2}

Research question \#2 asks, "What are teacher/school administrator knowledge, beliefs, and attitudes towards equity issues in education (generally) and at OSD specifically?" In this section I will discuss OSD educator definitions of equity and the two pedagogical approaches that were most frequently mentioned during the interviews I conducted, as well as observed in the classrooms visited.

Defining equity as access. Nearly all of the OSD educators that I spoke with defined equity similarly. Almost every participant described or used the word "access" when asked what equity in education meant to them. This is notable, as there seems to be a 
mostly common definition of the term "equity" across the district. The following four excerpts from interview transcripts show the relatively common definition of "equity in education" that seems to be prevalent across the district.

Equity means...that any child coming into my classroom, from wherever their background is, they all have equal access to what I'm trying to teach them, and that they have access to whatever they need, whatever tools or services they need in order to help them reach their greatest potential in education. (Alice, teacher, 2018)

Equity in education...means that all students have access to the curriculum and that the teacher is addressing the needs of all students, including historically underrepresented students, our students of color, our EL population. Basically for me, it means that I'm the one to level the playing field. That's what I pride myself in doing. (Larry, administrator, 2018)

Equity in education...I guess in simplest terms, equal access, right? Making sure that regardless of students' backgrounds, parental support, cultures, as well as, I don't know, historical background, financial background, socio-economic status. Whatever kids are coming into my classroom with, I want to make sure that they have equal access to success in school, whether that's able to access content, if it's feeling like they are represented, feeling like they are respected, and that they have a voice in the classroom. (Jane, teacher, 2018)

It means moving towards the idea that each child, regardless of where they were born, or what they look like, or what gender they identify with, will have as close as we can get to equal access to high-quality learning across the subject areas. (Toni, teacher, 2018)

\section{Student-centered teaching and pedagogy. A common thread that I discovered}

when coding interview transcripts and reviewing my observation notes was the notion of student-centered teaching. This concept was discussed in Chapter 2 as an in-school factor that results in more equitable educational outcomes for students. This concept was also prevalent during discussions with participants, as well as in the observations of classroom teaching. The concept of student-centered teaching also came up often during follow-up interviews with the teachers I observed. The following excerpts from 
interview transcripts illustrate how the concept of student-centered teaching was talked about in relation to equity issues in the classroom.

In my classroom I'm trying to adjust the curriculum, adjust the methods that I use to teach curriculum so that everyone has access. It's almost like there's this treasure box in the middle of my carpet in my classroom. I want everybody to reach into the treasure box and get the content they need for the day. So I need to make sure everybody's got the keys to get into it. (Elaine, teacher, 2018)

I like getting to know my kids, and really that shared decision-making. I also try, of course, to mix up my instructional moves, so thinking about who my kids are as learners and the best ways to bring out their individual strengths and their individual needs. Well, not bringing out their needs, but you know, support their needs. (Jane, teacher, 2018)

Student-centered teaching is often discussed in terms of offering students "voice" and "choice" in their own learning. The two passages below help to describe this pedagogical approach.

I'm very much a strong proponent of student voice, and student ownership, giving kids an opportunity to grow as individuals, giving kids an opportunity to make decisions in the classroom. It's very much a shared ownership, if not even more so on the student end. I want, I mean, from day one, kids are designing our classroom, designing their curriculum, making curricular instructional choices as well as kind of the day-to-day routine choices. (Jane, teacher, 2018)

If you're asking people to be a writer, then it seems like micromanaging to tell them to write about apples... That doesn't mean I don't have some times where I'm like, 'Hey, we're all writing about apples.' Once in a while that happens, but it's probably like $10 \%$ of my writing. The other part of my writing is choice. (Elaine, teacher, 2018)

Teaching in a student-centered way often means breaking from traditional instructional paradigms where teachers are considered the "holders of knowledge" or a "sage on the stage" (Danzig, Borman, Jones \& Wright, 2007; McLean 2012). Studentcentered teaching demands a shift in the teaching paradigm and a movement of the 
teacher towards becoming a "facilitator of learning" (Danzig, Borman, Jones \& Wright, 2007; McLean 2012). The passage below captures one teacher's perspective on the shift from the traditional pedagogical approach to a student-centered approach. Her view is that student-centered learning empowers all students and positively impacts equity by ensuring that all students have greater opportunities for success in school, regardless of prior experiences at school or previous levels of performance.

I've been trying to pull myself back as a teacher and be more of a facilitator and let kids own their learning more. I think that can help with equity too. I think also trying to see things through their eyes, trying to have those relationships with kids and trying to think about, for example, if I assign them to do something, who's going to have a hard time with that? Why they would have a hard time, and how can we eliminate those challenges? How can we make it so that everybody has access and everybody has that chance to be successful? (Ann, teacher, 2018)

Student-centered teaching isn't only about instruction but also reflects a shift in the way students are assessed and asked to demonstrate learning. The passage below captures this approach towards assessment of student learning.

I try to be more flexible with the way the kids do things and the way that they present their information. As time has passed, on an assessment it won't necessarily just be a written assessment. Maybe some kids will be able to record themselves speaking and that will still fulfill my need to assess that they have that content knowledge but it doesn't have to be that formal paper anymore. (Tracy, teacher, 2018)

This final passage demonstrates one educator's belief in the effectiveness of the student-centered approach and the impact it can have on improving educational outcomes for underserved student populations. It is a message of hope and optimism, believing that dedicated educators using student-centered pedagogical methods can indeed change the historically negative educational outcomes that have faced underserved student 
populations for decades. The passage also indicates the work that remains and the improvements that still need to be made.

I've seen what happens when you do give students the opportunity to succeed or when you give them access to the curriculum. I've seen how they can do just as well as their counterparts. But unfortunately, I don't think it's happening quite often or as much we would like. (Larry, administrator, 2018)

Culturally relevant pedagogy. Another common thread (in terms of teacher and administrator beliefs about equity) that was talked about and observed during classroom visits was the notion of culturally relevant pedagogy. This concept, also discussed in Chapter 2, was discussed as an in-school factor positively affecting educational outcomes for historically underserved student populations, and it came up repeatedly in my discussions with district educators and observations of teachers. The excerpts below are examples of OSD educator beliefs on the importance of culturally relevant pedagogy and the relationship between culturally relevant pedagogy and a reduction in overall disparities in educational outcomes for historically underserved students.

I try to figure out who my students are and what their real interests are and what their passions are and then get that into the curriculum. (Elaine, teacher, 2018)

Some teachers think of culturally relevant pedagogy in terms of offering a responsive classroom with regular meetings in which time is set-aside (every day) for students to sit in a circle and discuss issues and topics that are important to them.

We have a morning meeting, and I like that as an equalizer. We all come in, we sit in a circle. Every single day, we greet each other, by name...I like this structure...we do a little share, we have an activity... (Sally, teacher, 2018)

Other teachers grappled with the complexity of the concept of "culture" and trying to utilize pedagogical practices that are relevant and meaningful to students and their lives. 
It's not just about what we do, but empowering children to take what they need and to be the person they are, to respect different learning styles. It's so complicated. It's even... Well, I didn't say this earlier, but it's also about using different modalities. Different cultures and different kids need to move more, need to make more, need to hear more, need to see more. The more we think about how we all learn in different ways and the more respect we have for everybody's differences, I think that enables us to be more equitable. Equity is easy to say, but it's so much more complicated to do. I think that's something I've learned over years. (Ann, teacher, 2018)

My classroom communities are changing. I've seen that throughout my career...The kids not only...Families are different. Kids are changing. Life is becoming much more complicated and hard to kind of to navigate. Of course, not only culturally more diverse, but you know, families are more diverse. Then, kid's background experience is more diverse. It's not only looking at the surface level of like, you know, 'What's the ancestry of my students?' But it's more about looking at all of the different pieces that develop a student's culture, right? What culture really is beyond just sort of racial identity, or gender identity? (Jane, teacher, 2018)

Another teacher spoke about culturally relevant pedagogy in terms of giving students linguistic freedom when writing and expressing themselves. Freedom in terms of being able to express themselves in their writing in whatever language is most comfortable for them.

I want them to begin to think of themselves as writers. I want them to seriously go and be like, "I'm a writer. I write stuff." I think that they're more likely to perceive themselves as writers if they're doing it in native languages. I think they're more likely to see themselves that way, it's like that makes that almost very visceral connection between themselves and their identity as writers or as readers if they're doing that in genres, and topics, and languages that they have a very visceral connection to it. (Elaine, teacher, 2018)

The teacher-librarian I spoke to thought of culturally relevant pedagogy in terms of the books that she purchases for the school collection.

As a librarian, just making sure that the books that I purchase or the books that are already in the library represent all students in our community. (Avery, teacher, 2018) 
Summary. Regardless of their role in the district, OSD educators generally defined equity in education similarly and identified two critical approaches that epitomized their beliefs about their practice. By in large, student-centered and culturally relevant pedagogy were identified by OSD educators as pertinent to their attitudes and beliefs about equity and provide important categories for understanding how educators think about their roles and their aspirations to improve educational outcomes, particularly for historically underserved student populations. This theme will be discussed again in Chapter 5.

\section{Research Question \#3}

The next section presents findings around my third research question, "What factors do school site administrators and teachers say they have to manage when implementing initiatives aimed at reducing disparities in educational outcomes among their students?" In this section I identify the main areas in which OSD employees repeatedly identified the factors that needed to be managed in order to reduce the disparities in educational outcomes for their underserved student populations. All of the topics that OSD educators mentioned are also discussed in Chapter 2 and they include out-of school factors (both empirical and conceptual) as well as in-school factors (the lack of opportunities to discuss equity challenges they face in their work).

\section{Teacher/administrator perspectives on the relevance of out-of-school factors.}

The OSD educators interviewed mentioned lack of resources and issues relating to poverty as factors limiting their ability to reduce the disparities in educational outcomes for their underserved student populations. Some of the factors are truly specific to the 
dynamic of the OSD student population and the wide range of socio-economic diversity that exists in the community. The following excerpts offer some examples of the factors specific to OSD as well as other out-of-school factors mentioned by participants.

Our site has lots of diversity, and we try really hard, given the population we have is so diverse because we have kids that live in $\$ 4$ million houses next to kids that live in a shack. We try really hard to make it so that all of those kids have equal access, and that doesn't always mean the same things. (Toni, teacher, 2018)

I've worked in three different school districts and I've never seen such a disparity between scores and even social-emotional learning and supports. That was even before I interviewed and I looked at the school and district data it was shocking when you look at scores to know that the same kids are sitting in a class for seven hours a day but the outcomes look so different. And that's just academic outcomes. (Ally, administrator, 2018)

Just being in a district where I would say the differences between those kids that are disadvantaged or underserved versus the ones that come from very privileged families, the difference is so much more drastic than the previous district I was in, the differences between those students and what they have access to outside of school. (Cindy, teacher, 2018)

Just the outside things that I can't control. When they come to me and where they're at. I think, especially middle school, developmentally they're all over the place, sometimes they're just not ready for an activity, a specific activity. That's kind of hard to address. I also think that when I see them during the day really matters. I have a ton of kids in my first period class who just have a terrible time getting to school. Then they miss 20 minutes a day, which ends up being one class period a week. That's like $25 \%$ of their learning. (Tracy, teacher, 2018)

Even with the relative affluence in the OSD community and the comparatively high levels of funding the district controls, lack of resources are still mentioned as a factor that needs to be managed in order to achieve more equitable educational outcomes. To address the disparities in educational outcomes for underserved student populations a lot more funding is needed (see Chapter 2), even in a district like OSD. This sentiment is discussed in the excerpts below. 
Challenges: lack of resources in the classroom and outside of the classroom. In terms of personnel, being able to work with students that need extra time.

Challenges: money to buy supplies and things that are needed in the classroom to support all those different types of learning. Not just being able to teach them, but different tools, different modalities. I can't think of the word right now. Like having enough, say like computer equipment or iPads so that all the children have equal access to being able to use that, because I feel that really extends some of their learning, both ways extending it and helping them when they are struggling with it. (Alice, teacher, 2018)

Resources they come and go in terms of whether they're enough, in terms of challenges. Certainly we could, certainly we always need more time and money to help meet the needs of kids. (Ally, administrator, 2018)

Opportunity gap and politics. Another out-of-school factor mentioned by many

OSD educators as a factor needing to be managed and leading to the disparate

educational outcomes for underserved student populations relates to the opportunity gap

(discussed in Chapter 2). The following excerpts describe this phenomenon in OSD.

While we have excellent academic programs, excellent pedagogy, people are not starting from the same place with the same resources and same experience. So an equitable district would take that into account in attempting to provide, figure out what the students need when they come here, and not just assume that giving them what everybody else is given will lead to the same results. (Corey, administrator, 2018)

Even if it's just tutoring and camps and enrichment and all the stuff, kids are just coming into school with such a gap in their knowledge and experience that it almost makes the district's job harder to then close that gap because the gap starts out just so wide from their backgrounds and their experiences before they even get to school. It just opened my eyes I would say more to what creates the gap and what contributes to it and the challenges that that poses for districts beyond just resources and stuff. (Cindy, teacher, 2018)

Several other OSD educators also described the opportunity gap, but in much more specific terms, as it related to access to technology. The following excerpts describe the opportunity gap in OSD as it specifically relates to access to technology. Some scholars have also described this specific phenomenon as the "digital divide." 
We've gotten more digital. I think we're one-to-one in the classroom, so even though they don't have things at home, we use the computer a lot more and I see that kind of presenting some more challenges, but this also makes things more accessible for certain students... The biggest disparity I see, I think, is typing; typing and using Google Docs. I mean, I think that makes things faster for all students, but I think I've seen ... And this is all anecdotal, because I haven't really taken anything, but I see it kind of like the skills fall along socio-economic lines. Right, so the kids who are not as adept at using a computer and a laptop, specifically, with like the typing skills, and Google Drive, and Google Docs, usually have a lower socio-economic status. (Tracy, teacher, 2018)

What happens is, this unequal distribution of minutes starts to happen (in regards to access to technology within the classroom). The kid that's familiar with the tech has it longer, and the kid that is not familiar has it less, and less, and less. It's not because anybody's doing anything wrong. (Lacy, teacher, 2018)

A lot of the resources that we have for kids to help boost them include, let's say, apps or programs on the computer that kids can access from home. Some kids that are economically disadvantaged might not have access to that or might not have a parent that can, let's say facilitate that for them. (Cindy, teacher, 2018)

There is indeed a specific political climate fairly unique to OSD because of the wide range in socio-economic levels present within the community. Some of the specifics of this dynamic are discussed in the excerpts below.

I would say that equity looks like the ability to give responses to intervention, along with RTI services to those kids that really need it, while also prioritizing, as a site, student needs versus the needs driven by parents, if that makes sense. That's the constant struggle in Ocotillo is that you have, let's say we look at the data sitewide and we say, okay, we're going to provide a math intervention to the bottom 20 kids. Then you have Susie and Johnny's parents over here like, 'Hey, I know you have this math intervention. My student's below.' Even if that child might be in the numbers above the bottom 20, and I've seen this happen, they fill spots because the parents advocate and the parents push. There's that parent pressure. I feel like the drive is there among the staff to really be equitable in terms of allocating resources based on need, but sometimes those other factors come into play and your hands are tied. (Cindy, teacher, 2018)

I actually thought about this. Practically speaking, it looks like the way I spend my minutes, because in Ocotillo people get kind of pushy with what they want, and 'Talk to my kid about this,' and 'You need to do this extra thing for this kid,' and so all the kids who have parents who are pushing on me started to get more of 
my minutes. I realize that's not okay...I don't allow myself to sit or spend lots of time unless it's a kid that really needs me...it's people who push different agendas for kids that may not need as much as other kids. (Lacy, teacher, 2018)

My findings validate the power of out-of-school factors as a significant challenge that educators face when trying to generate more equitable educational outcomes for underserved student populations. Trying to account for the wide range of experiences and opportunities that different students come to school with was a factor that many of the educators I spoke to said they had to deal with regularly. With the advances in technology and access to tools that enhance learning becoming more and more important, a new dimension in dealing with the opportunity gap has emerged. When you mix in the political battles that occur every time a decision about allocation of resources is made, you begin to see some of the factors that need to be managed in order to produce more equitable educational outcomes in a community like Ocotillo.

Opportunities to discuss equity. The strongest finding (because of the number of times that it was mentioned, as well as the amount of time it was talked about) that I uncovered during my interviews related to the desire to allocate more time towards having open discussions about equity as it related to school practices. The following excerpts offer some examples of what was mentioned by the OSD educators I spoke to.

At our school, equity doesn't necessarily come up in conversation very often. It's something, being part of a leadership team, that's one of my goals, is to continue to bring that up in as a part of our conversation in the work that we do. But we're very much as a site right now, very focused on new initiatives, working on Reader's Workshop, Writers Workshop, the new math curriculum implementation, so conversations around equity sort of get pushed to the side, not seen as our priority...In the school, it's always a matter of something else that we need to think about rather than being the first thing that we need to think about in order to do everything else. (Jane, teacher, 2018) 
If I wanted to not be equitable, it wouldn't be hard. I could just do what ever I wanted and just not. It's not really a conversation. In my previous district we always had conversations about it, so there was a momentum that was easy to get into. All you had to do was step into a conversation with somebody, and then you would be pulled along into that vein, but here it's like you have to be independently driven in order to have a frame of mind where every day that's something you think of...It feels like I'm starting a conversation. All the time I'm starting the conversation, and that's just to get people to be kind of comfortable with it... I hear teachers like me trying to bring it up. Can we talk about equity issues? Then it gets diverted, and then another teacher says, 'Oh, I'd like to talk about that,' and it gets diverted. It's not that there's not interest... you need to have a collective effort by multiple people in order to drive something. When we sort of get talking and brewing about something, it gets diverted really quickly, or it's why we can't do it and why we're not going to do it, or it's this is more important, or it's the district said you have to, so that's what we do. (Lacy, teacher, 2018)

In my own classroom I have total autonomy so I can do all this badass stuff I want to do. And then I fool myself that maybe I'm doing the right thing. It's in this context that's not in communication with other people on site. There are those limitations of time and resources to talk about it. In my classroom I have full control. Further out, I have less control. Three years, four years ago I used to think, 'Well, what she did was wrong, what I'm doing is right.' Now I'm beginning to wonder, 'Maybe it's not black and white. Maybe it's a conversation we need to be having.' (Elaine, teacher, 2018)

There's no shortage of caring by the teachers for their kids here. What we don't do is spend some time thinking about what equity practice is. Not that we need one more thing to add to our pile, but I think it would be nice to think about what strategies are effective for leveling the playing field, and addressing issues of equity on a campus. I wish that we did a little bit more of that as a staff, so we could have these conversations about how our biases affect outcomes for our students, about what we could be doing proactively to support our students, rather than after they're failing. And there are no good answers, and no easy answers when it comes to equity but the conversations, I think, help to bring awareness and I think it's a cultural shift to think about equity on a regular basis. (Ann, teacher, 2018)

While OSD educators definitely mentioned a desire to discuss equity issues with their colleagues, the need for discussions about race and class (and their impact on educational outcomes), in the larger community was also identified. 
I think that equity is still an unrealized aspiration. I know that we have district committees and goals trying to write equity plans. What I've seen is that the district, the community struggles with trying to understand essentially what it is that they're trying to solve, what the problem is that they're trying to solve. To some degree, it's an invisible problem to a lot of people. For the people who experience it, and the families, and the students who come from less resourced backgrounds, the struggle for them is very real. Sadly, there's a lot of marginalization still in this community. I think that that is, it's not enough just to bring people into meetings, but their voices have to be strong, and people have to listen to what they're actually saying that they need. (Corey, administrator, 2018)

Summary. When asked about the factors they needed to manage in order to implement initiatives aimed at reducing the disparities in educational outcomes for underserved student populations, OSD educators discussed many issues. These issues included: 1. Needing to address out-of-school factors relating to poverty (and the need for more school funding), 2. Needing to address the opportunity gap present in the students they enroll (specifically when it comes to access and experience with technology), and 3. Navigating the political landscape of the district. Most of all, OSD educators expressed a desire to have more time set aside to discuss equity issues as they relate to their school site. This desire is rooted in fact. When reviewing various agendas I collected from different school sites and departments I only found only one example of an agenda item directly related to equity. The vast majority of the agenda items related to matters of compliance, logistics, or procedures, a theme that will be discussed further in Chapter 5 .

\section{Research Question \#4}

My final research question asked participants how the district initiative to reduce disparities in educational outcomes changed the way they operationalize and reflect on their practice. From my interviews and observations, I found four aspects of MATD 
recommendations that participants indicated as factors that have initiated a change in their practice or have lead them to reflect on their practice. These four areas include 1. Streamlining of curriculum, 2. Training in unconscious bias, 3. Addition of HomeSchool Liaisons, and 4. Expanding kindergarten to an all-day structure.

Streamlined curriculum. OSD has made efforts to streamline their curriculum in order to make it more coherent and vertically aligned. These efforts came up in the interviews I conducted as well as the classroom observations. During classroom visits, the coherence of the lessons was noticeable as was the consistency in the pedagogical approaches being used. A streamlined and coherent curriculum was mentioned in Chapter 2 as an in-school factor leading to more equitable educational outcomes and was also recommendation of the MATD. When asked about the benefits of streamlining curriculum, several of the teachers I spoke to pointed to the positive impact on academic outcomes.

I do most of my work through workshop so that I'm teaching a mini lesson to the whole class to teach them a strategy for reading, writing, or math. Then, I'm either pulling them into small groups to reteach, or extend their thinking or learning on that concept, depending on where they are, or individual conferences, going over things that they need, or pulling them to review, extend their thinking. (Alice, teacher, 2018)

(The workshop model) has put a really nice structure to the strategies I teach. I used to try strategies, but I didn't always have the kids in the right levels that I was trying to teach. They were trying to use it on a level that was either way too high, or the text didn't lend itself to something. I think it's improved my level of teaching. (Lacy, teacher, 2018)

One of the participants noticed the benefits of curricular coherence as it pertained to the after school math intervention program at her site. 
We were using an after-school math program that did not match the math program that the teachers were using. Now the teachers are using the same math program as our after-school math program. At least the kids are hearing the same language after school and during the school day, which I think is helpful. (Avery, teacher, 2018)

Even with the improvements across the district (as it pertains to curricular coherence and strategic district-wide efforts), several OSD educators admitted that there is still work to be done in order to unlock the full benefits of a streamlined curriculum and the systematic large-scale approach to the challenges facing the district.

I think in a perfect world, if everybody were actually being reasonably faithful to the curriculum that would be enormously beneficial...Here, I'd say most teachers are on board, but not everybody. The few who aren't do cause some problems, I think, for the rest of us. So you'll get a class where two thirds of the kids know what boxes and bullets are, and the other third has no idea. Or two thirds of the kids have done number talks and one third hasn't. So yeah, I think it's an unfortunate mix when some people are hanging onto their own autonomy and then everyone else is trying to be a team player. (Sally, teacher, 2018)

Taking a set of recommendations and turning them into action plans is not something that this district is very good at. And I think that that's because it requires you to come together and have a shared vision. And I think that decentralized management style has meant that we've never really tried to tackle something big altogether. So what I've seen for the last two years is a lot of challenges as people try to figure out what the recommendations mean, how they get implemented, where responsibility and authority lies to promote the recommendations moving forward. (Corey, administrator, 2018)

Unconscious bias training. Another MATD recommendation mentioned by several participants included the training in "unconscious bias," which all OSD employees were required to attend. Several of the participants reflected on the impact that the training had on their practice. The excerpts below provide several examples of this.

The unconscious bias training that I went to last year was really insightful and I'm really glad I went to that. Not just as a teacher, but just as a person... you don't want your biases one way or the other to make you unavailable to some segment of your 
classroom. Every single kid who walks in the door needs to have access to me and access to my belief that they are valued greatly. (Elaine, teacher, 2018)

I think everyone has biases. And I have biases. And the training that we did with (unconscious bias)...that sort of opened my mind. The training that we had on LGBQT issues opened my mind...Yes. So, that is something also that I've been thinking about. (Sally, teacher, 2018)

I think first of all, I have my own biases that I have to overcome. I try to be fair and equitable, but I know even I have unconscious biases that I have to address, that I have to check myself. I think for example, one of the things that I've been working really hard on is in reading, we ask them to make inferences. It's so easy to try to get them to come to the same inference that I would come to, but if I'm really being culturally responsive, I should also realize that it's not that they can't make inferences. Maybe they just don't have the same prior knowledge that I do, that they're coming up with a different answer because their prior knowledge plus the text creates a different inference. That's been something that I've been working really hard on, not shooting down kids' ideas, but pausing and trying to think about what did they bring to bear to come up with that idea, so that I value the work that they are doing and the skill that they do have, rather than judging that it's not what I would expect them to come up with. (Ann, teacher, 2018)

Other participants also noted the unconscious bias training and the reflective impact

that it had on their practice. They also viewed it as a first step requiring more

conversations and ongoing follow-up for the organization at large.

Now we have to have two days mandatory unconscious bias trainings, and it's always after the fact, right? My impression is this, what it seems like is that it is always after the fact like, 'Oh, yeah. This happened, so we probably need to do a little patch work that teachers need,' but then it never comes back to it. It needs to be something that is a part of our every-day practice. It needs to be something that is really guiding every decision that we make with kids, and it's not. (Jane, teacher, 2018)

Home-school liaisons. A third MATD recommendation that participants mentioned as having impacted the way that they operationalize their practice included the hiring of additional staffing in the form of Home-School Liaisons. The MATD Task Force recommendations lead to the hiring of additional personnel with their purpose being 
outreach and communication with families of underserved student populations. OSD refers to these additional staff members as Home-School Liaisons. Several of the participants took notice of this additional staffing and mentioned it during their interviews.

Right now I have a family liaison specialist who's been amazing this year. I'm able to use her for a lot of things. Just for communication. It's not just language, it's also, 'How does this system work, or which meeting should I go to?' (Elaine, teacher, 2018)

The Home-School Liaisons have made outreach efforts from teachers and school sites easier and more effective. This was one of the goals of the MATD Task Force. Teachers that want to make sure that all of the families that they serve are being communicated with lean on the Home-School Liaisons as a partner to link families to the school community.

(I need to be) making sure that I'm reaching all students, making sure that things are as equal as they can be for all my students, whether that means books at home, phone calls to parents. When I was a teacher, some parents were very hard to get in touch with through email, so I would make special phone calls. I went above and beyond, sometimes just making sure that parents, especially the underserved children, making sure that those parents attended conferences, because you could send out one or two emails or send two papers home and nothing comes back. I feel like just through communication with families, that it is important to go above and beyond and to get those parents into the classroom for conferences, as well as for other opportunities that we have at school, whether it is a literacy night or a classroom bonding experience like a potluck, making sure that all parents attended. (Avery, teacher, 2018)

Using the Home-School Liaison has helped schedule conferences. We went (on an overnight field trip) to Coloma again. (The Home-School Liaison helped with) offering scholarships, chasing down parents, begging them to have sleeping bags on hand. (Sally, teacher, 2018)

All-day kindergarten. One of the most publicized of the MATD Task Force recommendations regarded changing the OSD kindergarten schedule to an all-day format. 
There was a good deal of discussion around the implementation of this change both in the community and between kindergarten teachers. Ultimately the decision was made to go ahead with the all-day kindergarten schedule. The vast majority of the kindergarten teachers in the district opposed the decision. The kindergarten teacher that was interviewed for this study was in favor of the all-day kindergarten schedule and spoke at length on the topic. She summarized the district decision to go to all-day kindergarten and the impact it had on her practice in the excerpt below.

One of the key MATD initiatives was full-day kindergarten. I was the sole kindergarten teacher in the meeting in favor of full-day kindergarten for everybody. There were a lot of no-so-pleasant repercussions from those set of meetings. It hasn't affected my practice because we were the only site that had full-day kindergarten prior to that, and I was the only teacher in the district that had taught both models...it just is, for every kid, it's so much less confusing, it allows for more time for play, which also helps kids from different backgrounds play with one another. And for a lot of our kids that don't have a safe place to play in their backyard at home, or lots of toys, they get lots of opportunities to play and use language in a productive way, and learn those kinds of skills.

So I'm glad we went with the full-day model, and don't understand how anybody could teach a half-day or extended day model anymore, and not be so stressed out all the time about getting to everything you need to get to in order to make sure everybody's ready to go on...It makes the kinder day a little more mellow, because, you have time in the afternoon. Like, the number one thing I hear most teachers complain about it, all the time is, I don't have time for blah. I don't have time for blah. I don't have time for blah. Well, now I have time for blah...Our kids need more guided reading and literacy activities, than just in readers workshop, and writers workshop and shared reading. They need time to read the room, and do listening center, and have another session with me. Which also gives us time, once again, for the reading specialist to push in, because nobody else needs or wants the reading specialist to push them in the afternoon. It gives us time for choice time, almost every day, and I'm old, so I'm old fashioned. I feel like kids still really need the social language of having some time to play. (Toni, teacher, 2018)

Summary. When asked about how district initiatives to improve educational outcomes have impacted the way they operationalize and reflect on their practice, OSD 
employees referenced four significant changes that resulted from MATD Task Force recommendations. The four areas included efforts to streamline curriculum, training in unconscious bias, adding Home-School Liaisons, and changing to an all-day kindergarten schedule across the district. The impact of these MATD Task Force recommendations has yet to be determined, but for the participants in this study, the four areas mentioned in the sections above have had a definite impact on their attitudes, beliefs, and practices. 


\section{Chapter 5}

\section{Summary, Conclusions, and Recommendations}

In this chapter I will provide a summary of findings and discuss recommendations for next steps for OSD in an effort to assist them on their desired journey towards attaining more equitable outcomes for their underserved student populations. The discussion and recommendations will focus on student-centered teaching, culturally relevant pedagogy, the opportunity gap, and opportunities for open discussions about race and class.

\section{Introduction}

The findings for Research Question \#1, around the lack of progress observed over the last three years of disaggregated state testing data in OSD, may confirm the argument made previously (in Chapter 2) that standardized testing itself might actually add to the disparities in educational outcomes for underserved student populations. The findings might also confirm the argument made previously (also in Chapter 2) that standardized test scores are generally insensitive to improved practice because out-of-school factors are so pervasive. To take it a step further, the lack of progress seen in the three years of disaggregated SBAC data might add to the line of thinking that out-of-school factors are so strong that no school initiative (even the most extensive and most well-intentioned) would be able to affect standardized test scores. With all of that said, the MATD Task Force initiative is still in its infancy stage (relatively speaking) and many of the recommendations have not even begun implementation, nor have yet to be fully implemented. Changing the direction of an organization the size of OSD is no easy or simple task and it should be expected that it would take many years of faithful 
implementation to even begin to see differences in historically entrenched educational outcomes and disparities.

Summary of findings. Figure 4 provides a summary of the findings in this study. Each research question is linked to the pertinent findings.

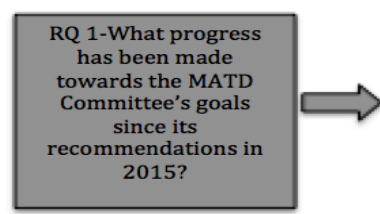

RQ 2-What are teacher/schoo administrator knowledge, beliefs, and attitudes towards equity issues in education (generally) and at Ocotillo School District specifically?

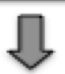

1.) Disaggregated SBAC Results (2015-2017)-Limited progress towards OSD goals of increasing the percentage of historically underserved students performing at or above grade level and reducing the percentage of historically underserved students below grade level.

2.) Percentages of underserved students taking advanced level high school courses (2015-2017)-Increase in the percentage of African-American students in Advanced Placement Courses but a decrease in the percentage of Hispanic/Latino students.

3.) Disaggregated Graduation Rates (2016-2017)-"High" graduation rates and improvement from 2016 to 2017 for African-American students. "Low" and "medium" graduation rates for socioeconomically disadvantaged students and Hispanic/Latino students respectively and decreasing from 2016-2017.

4.) Number of referrals for underserved students to Alta Vista High School (2016-2017)-"Low" suspension rates for socioeconomically disadvantaged students and Hispanic/Latino students respectively and "high" and increasing suspension rates (from 2016 to 2017) for African-American students.

5.) Disaggregated student connectedness results on the California Healthy Kids Survey (2016-2017)-Significantly higher rates of chronic absenteeism for African-American and Hispanic/Latino students than other student groups.
1.) Define equity as access

2.) Value student-centered teaching

3.) Value culturally relevant pedagogy

\begin{tabular}{|c|}
\hline RQ 3-What factors do \\
administrators and \\
teachers say they \\
have to manage when \\
implementing \\
initiatives aimed at \\
reducing disparities \\
in educational \\
outcomes among \\
their students? \\
\hline
\end{tabular}

Recommendations

1.) Build on student-centered approach

2.) Build on culturally-relevant pedagogy

3.) Focus on closing the "Opportunity Gap" particularly the "Digital Use Divide"

4.) Create opportunities for open discussions about race and class

1.) Out of School Factors
1.) Streamlined Curriculum

2.) Unconscious Bias Training

3.) Home-School Liaisons

4.) All-Day Kindergarten

2.) Opportunity Gap (Digital Divide) and Local Politics

3) Lack of Opportunities to Discuss Equity

Figure 4. The figure provides a summary of the findings in this study with next steps for research as well as recommendations for practice. 


\section{Reciprocity and the future of Ocotillo School District's journey. Upon}

completion of this dissertation I plan to provide the OSD Research Department with a final copy of this work with the hopes that any insights gathered can be used to further the district's ongoing quest to achieve more equitable outcomes for their underserved student populations. As I complete this work, OSD is searching for a new superintendent to lead the district. Hopefully, the new superintendent will share the passion and desire for equity held by the former superintendent. In this way, the spirit, intent, and work of the MATD Task Force will continue for years to come.

Conclusion. Interestingly, most of the participants mentioned aspects of MATD Task Force recommendations (such as unconscious bias training and the hiring of homeschool liaisons) without attributing the change in their practice or their personal reflection to the MATD Task Force recommendations. Among the participants, there was very little knowledge of the MATD Task Force and the recommendations associated with it. However, several participants mentioned factors that lead to a change in their practice or a self-reflection on their practice that can be directly attributed to the MATD (the participants just had no knowledge of the connection).

\section{Recommendations and Discussion}

Student-centered teaching. Based on the findings of this study, there are definite areas of strength to build on in OSD. When it comes to strategies to improve educational outcomes for underserved student populations, there are two encouraging practices that OSD educators are currently utilizing. One of these practices is student-centered teaching. The OSD teachers that I spoke to believed that student-centered teaching is an 
effective strategy to meet the needs of their diverse student population. Research would confirm this belief as a student-centered approach has been shown to have a high impact on student achievement and learning (Hattie, 2012). OSD leadership should recognize this strength and foster it to ensure expansion of the approach to all classrooms and school sites.

If all students receive improved instruction from a student-centered approach, it is a practice that should be expanded and spread across the district. Even if some disparities continue to exist while educational outcomes for all students improve, it would justify additional time and energy devoted to the expansion and development of a studentcentered approach. Continuing to invest in instructional coaches would be an effective way to spread best practices such as student-centered teaching (Senge et al., 2012).

As mentioned in Chapter 2, a student-centered approach can and should also be applied towards assessment practices. Even though there has been a lack of progress in state testing, it does not mean that there has not been progress in student learning. Student progress measures beyond SBAC scores should continue to be utilized and expanded, as some educational researchers would contend that they are more valid measures of student learning than state standardized assessments anyway (Robinson, 2011).

The workshop-teaching model being utilized by elementary teachers across the district is an incredibly promising practice in that is rooted in the student-centered approach. Maximizing student voice and choice has both short-term and long-term benefits for students. From the teacher interviews conducted and the classroom 
observations made, it is clear that the workshop model provides students freedom of expression and motivates and engages students to develop their reading and writing skills.

Student-centered teaching and leadership offers a message of hope. Student-centered pedagogy presents a more optimistic view of teaching and learning, and teachers and administrators who embrace the approach receive some solace from the negativity that surrounds results from state standardized tests. Teachers know when their students are learning regardless of what SBAC results tell them. For many reasons (some of which are outlined in Chapter 2), SBAC results do not appropriately measure what engaged students actually get from their classes. In the end, the disparities in educational outcomes (especially outcomes on state assessments) are as much a function of a competitive education system trying to stratify students than it is of the actual teaching and learning that goes on in school (Bowles \& Gintis, 2012).

Culturally relevant pedagogy. Another area of strength for OSD is rooted in the belief of its teachers in culturally relevant pedagogy. In this practice, teachers design their lessons and plan to incorporate the interests of their students as much as possible. The theory is for teachers to build on and to connect new learning to the knowledge that their students are already coming to school with. For example, for language learners given the freedom to write and express themselves in their native language, the long-term benefits of building efficacy and confidence are more valuable than pushing them to acquire English as fast as possible (even though doing so may yield short term results on state standardized assessments). 
Educational research has shown that utilizing culturally relevant pedagogy is an effective practice for improving educational outcomes for students (particularly students of color and students from low socio-economic backgrounds) (Ladson-Billings, 1995). OSD should also recognize this strength and work to ensure that the approach spreads to all classrooms and school sites the same way they use their instructional coaches to develop other instructional approaches. The ability to effectively employ culturally relevant pedagogy stems from a mindset in which diversity is viewed as a resource (as opposed to a limitation) and students are valued as individuals with unique social and historical experiences (as opposed to categorizing students into larger ethnic or racial categories) (Gutiérrez \& Rogoff, 2003).

Focus on closing the opportunity gap. One area of focus that OSD educators have identified as necessary to address in order to attain more equitable educational outcomes for underserved students is the opportunity gap. OSD students come to school with an incredibly wide range of experiences (probably more so than most districts). It is critical for administrators and teachers to understand the complexity and nuances around the differences between the opportunity gap and achievement gaps without relying on the opportunity gap as an excuse for not serving the lowest performing students in their district. To achieve better educational outcomes for underserved student populations, OSD should focus on closing the opportunity gap. As we plunge further into the $21^{\text {st }}$ Century and technology becomes more connected to the learning experience of students, OSD should focus on increasing opportunities for all students to utilize technology to enhance their learning. 
The focus on closing the digital divide needs to be multi-faceted. First and foremost, the issue of access needs to be addressed. This includes both access to devices at home and at school as well as access to broadband networks for high-speed Internet access. The second component to addressing the digital divide includes developing digital literacy skills, technical skills like keyboarding and competency using necessary applications, as well as skills focused on executive functioning as it relates to technology integration. It is important to note that the way technology is utilized is as important as access. In many ways, access to technology has spread across socio-economic boundaries, but the way technology is used varies. Some educational researchers have found that students from low socio-economic backgrounds utilize technology for games and activities that do not require higher order thinking skills where as students from higher socio-economic backgrounds utilize technology in more advanced ways (Cheng, 2017). In order for the digital divide to be effectively reduced in educational settings, a multi-faceted approach is necessary (Cohron, 2015).

Opportunities to have open conversations about race and class. From the findings in this study, OSD needs to make equity a real and tangible emphasis for the district. This needs to happen by dedicating time during staff meetings to openly discuss issues of equity that impact the work of staff members throughout the district. Far too often, leadership, because of fear of discomfort, or inexperience with the topics, avoids issues of race and class. If real progress is to be made, these issues need to be at the forefront of conversations and discussed with regularity and frequency (Singleton \& Litton, 2006). The regular conversations should happen with district staff as well as 
community members. As stated previously, communities that have been able to openly discuss how students of different races experience teaching and learning in public forums have been able to reduce their racial achievement gaps (Singleton \& Litton, 2006).

My findings show that many OSD educators recognize the need for more open discussions around topics like race and class and their effects on schooling and have a strong desire for it. While it may make some staff members and district leaders uncomfortable, it seems like a critical and logical next step for OSD on its desired journey for more equitable outcomes for its underserved student populations.

Recommendations for leadership and administrative practice. The findings of this study indicate that a root cause of the disparities in educational outcomes in OSD still exists in that a "narrative of bias" still exists in the schools and community. This "narrative of bias" cannot realistically be reversed in three years and issues relating to the progress of underserved student populations are difficult to confront. A number of the recommendations of the MATD Task Force seem to have been implemented at a compliance level. My recommendation for the district administration would be to continue to work towards meaningful implementation of the recommendations and to closely monitor the impact on student outcomes.

Specifically, I would suggest the district leadership work to help staff develop a deeper understanding of the East Ocotillo community as well as the socio-economically disadvantaged neighborhoods within Ocotillo. Part of paying attention to equity would be for teachers and administrators to have a deeper understanding of the history of the community as well as the current conditions many of their students face. Most Ocotillo 
teachers and administrators drive to school and have never even walked through the communities where many of their students actually live. Spending time to learn about the community in this way may change how district employees view some of the children they serve and help them look at the students in a more positive (asset based) way.

In addition, OSD administrators should be empowered to create spaces and carve out time to continuously discuss issues of equity with their staffs and their school communities. Leadership cannot and should not be afraid to have and facilitate potentially uncomfortable and challenging conversations. Administrators should also have the courage and support to challenge elite parents trying to take advantage of the school system to divert the maximum amount of resources towards their own children. Equity is about directing resources in ways that benefit the students that need it most.

Finally, I would recommend that the district explore discipline policies that are less punitive. The data would indicate the current practices around school discipline seem to be working against some of the underserved student populations in that certain student groups are being suspended at disproportionate rates. Exploring and potentially implementing discipline policies like restorative justice that keep students form being removed from classrooms seems like an investment worth making.

Next steps for future research. As previously mentioned, OSD is still relatively early in its implementation process for the MATD Task Force initiative. Most of the original 12 MATD Task Force recommendations have been implemented but some of the recommendations have only been partially implemented or have yet to be implemented at all. Even with the recommendations that have been implemented, a lot more time to fully 
assess the effectiveness of implementation will be needed. Three years is simply not enough time to make an assessment on the effectiveness of these significant changes, especially in an organization as large as OSD. Continuing the study and making it a longitudinal study over a longer period of time (5-10 years) has great potential for more extensive findings.

Expanding the number of participants and selecting participants from the remaining schools in the district (including the two high schools) would also add more insights to the findings. Perhaps a survey to all staff members asking for responses to similar research questions would offer more extensive insights and findings. Expanding the study to include student and family interviews/perspectives could add yet another potentially informative dimension to the study. 


\section{References}

Anyon, J. (1980). Social class and the hidden curriculum of work. Journal of Education, 162(1), 67-92.

$\mathrm{Au}, \mathrm{W}$. (2016). Meritocracy 2.0: High-stakes, standardized testing as a racial project of neoliberal multiculturalism. Educational Policy, 30(1), 39-62.

Auster, E. R., \& Ruebottom, T. (2013). Navigating the politics and emotions of change. MIT Sloan Management Review, 54(4), 31.

Battilana, J., \& Casciaro, T. (2013). The network secrets of great change agents. Harvard Business Review, 91(7-8), 62-68.

Bernal, D. D., \& Aleman Jr, E. (2017). Transforming educational pathways for Chicana/o students: A critical race feminista praxis. New York, NY: Teachers College Press.

Berliner, D.C. (2009). Poverty and potential: Out-of-school factors and school success. Boulder and Tempe: Education and the Public Interest Center \& Education Policy Research Unit. Retrieved from http://epicpolicy.org/publication/poverty-and-potential

Berliner, D. C., \& Biddle, B. J. (1995). The manufactured crisis: Myths, fraud, and the attack on America's public schools. Reading, Mass: Addison-Wesley.

Berliner, D.C., \& Glass, G.V. (2014). 50 myths \& lies that threaten America's public schools. New York, NY: Teachers College Press.

Bourdieu, P. (2011). The forms of capital. Cultural Theory: An Anthology, 1, 81-93. Madden, MA: Wiley-Blackwell.

Bowles, S., \& Gintis, H. (2012). Democracy and capitalism: Property, community, and the contradictions of modern social thought. New York: Routledge.

Brewer, C., Knoeppel, R. C., \& Lindle, J. C. (2015). Consequential validity of accountability policy: Public understanding of assessments. Educational Policy, 29(5), 711-745.

California Department of Education (2016). California Standards Test Results. (n.d.). Retrieved from http://www.cde.ca.gov/ 
Cheng, P. L. (2017). Professional learning community (PLC): Technology integration at a title I elementary school (Doctoral dissertation). Retrieved from https://library.sjsu.edu

Cohron, M. (2015). The continuing digital divide in the United States. The Serials Librarian, 69(1), 77-86.

Coleman, J. (1968). The concept of equality of educational opportunity. Harvard Educational Review, 38(1), 7-22.

Danzig, A. B., Borman, K. M., Jones, B. A., \& Wright, W. F. (2007). Learner-centered leadership: Research, policy, and practice. New York: Routledge.

Darling-Hammond, L., Wilhoit, G., \& Pittenger, L. (2014). Accountability for college and career readiness: Developing a new paradigm. Education Policy Analysis Archives/Archivos Analiticos de Politicas Educativas, 22, 86. doi:http://dx.doi.org/10.14507/epaa.v22n86.2014

DiMaggio, P. J., \& Powell, W. W. (2000). The iron cage revisited: Institutional isomorphism and collective rationality in organizational fields. Economics Meets Sociology in Strategic Management, 17, 143-166. doi: 10.1016/S07423322(00)17011-1

Ed-Data Education Data Partnership (n.d.). Retrieved from http://www.ed-data.org

Edmonds, R. (1986). Characteristics of effective schools. The School Achievement of Minority Children: New Perspectives, 93-104.

Ferguson R., Hackman S., Hanna R., Ballantine, A. (2008, December). Raising Achievement and Closing Gaps in Whole School Systems: Recent Advances in Research and Practice. Report on the 2008 Annual Conference of the Achievement Gap Initiative at Harvard University. Retrieved from http://www.agi.harvard.edu

Gandara, P. and Contreras, F. (2010). The Latino education crisis: The consequences of failed social policies. Harvard University Press.

García, E. and Öztürk, M. (2018). An asset-based approach to the education of Latinos: Understanding gaps and advances. New York, NY: Routledge. 
Gerzon, M. (2006). Leading through conflict. Boston, MA: Harvard Business School Press.

Glass, G. V (2008). Fertilizers, pills, and magnetic strips: The fate of public education in America. Charlotte, NC: Information Age Publishing.

González, N., Moll, L. C., \& Amanti, C. (Eds.). (2006). Funds of knowledge: Theorizing practices in households, communities, and classrooms. Mahwah, NJ: Routledge.

Green, T. L. (2017). Community-based equity audits: A practical approach for educational leaders to support equitable community-school improvements. Educational Administration Quarterly, 53(1), 3-39.

Gutiérrez, K. D., \& Rogoff, B. (2003). Cultural ways of learning: Individual traits or repertoires of practice. Educational Researcher, 32(5), 19-25.

Hamilton, L. (2003). Chapter 2: Assessment as a policy tool. Review of Research in Education, 27(1), 25-68.

Hattie, John. (2012). Visible learning for teachers: Maximizing impact on learning. New York, NY: Routlege.

Haycock, K. (2006). No more invisible kids. Educational Leadership, 64(3), 38-42.

Kirst, M.W.\& Wirt, F.W. (2009). The political dynamics of American education (4th ed.). Richmond, CA: McCutchan Publishing Corporation.

Ladson-Billings, G. (1995). Toward a theory of culturally relevant pedagogy. American Educational Research Journal, 32(3), 465-491.

Ladson-Billings, G. (2006). From the achievement gap to the education debt: Understanding achievement in US schools. Educational Researcher. https://doi.org/10.3102/0013189X035007003

Lit, Ira W. (2009). The bus kids: children's experiences with voluntary desegregation. New Haven: Yale University Press

McIntosh, P. (1988, July/August). White privilege: unpacking the invisible knapsack. Peace and Freedom Magazine, 10-12. Retrieved from https://nationalseedproject.org/white-privilege-unpacking-the-invisible-knapsack 
McLean, A. C. (2012). Destroying the teacher: The need for learner-centered teaching. English Teaching Forum 50(1), 32-35.

Merton, R. K. (1968). Social theory and social structure. New York, NY: Simon and Schuster.

Milner, R. (2012). Beyond a test score: explaining opportunity gaps in educational practice. Journal of Black Studies, 43(6), 693-718.

Mitchell, K. (2011). Something's amiss in the international race and rankings. School Administrator, 68(9), 40-41.

Morgan, P. L., Farkas, G., \& Hibel, J. (2008). Matthew effects for whom?. Learning Disability Quarterly, 31(4), 187-198.

National Center for Education Statistics (n.d.). Retrieved from https://nces.ed.gov

Nave, Bill. (Ed.) (2015). Student-centered learning: Nine classrooms in action. Cambridge, MA: Harvard Education Press.

Nichols, S., \& Berliner, D.C. (2007). Collateral damage. Cambridge, Massachusetts: Harvard Education Press.

Oakes, J., Maier, A., \& Daniel, J. (2017). Community schools: An evidence-based strategy for equitable school improvement. Boulder, CO: National Education Policy Center.

Ocotillo School District Minority Achievement and Talent Development Advisory Committee Report to the Board of Education. (2015, May). Confidential.

Olszewski-Kubilius, P., \& Clarenbach, J. (2014). Closing the opportunity gap: Program factors contributing to academic success in culturally different youth. Gifted Child Today, 37(2), 103-110.

Pallas, A. M., Entwisle, D. R., Alexander, K. L., \& Stluka, M. F. (1994). Ability-group effects: Instructional, social, or institutional?. Sociology of Education, 27-46.

Pearson Index-Which countries have the best schools? (n.d.). Retrieved from http://www.thelearningcurve.pearson.com 
Popham, W. J. (1997). Consequential validity: Right concern-wrong concept. Educational Measurement: Issues and practice, 16(2), 9-13.

Robinson, V. (2011). Student-centered leadership. San Francisco: Jossey-Bass.

Rutter, M. (1982). Fifteen thousand hours: Secondary schools and their effects on children. Cambridge, MA: Harvard University Press.

Schaffter, H. (2001). Postconviction DNA evidence: A 500 pound gorilla in state courts. Drake L. Rev., 50, 695.

Senge, P., Cambron-McCabe, N., Lucas, T., Smith, B., Dutton, J., \& Kleiner, A. (2012). (Rev Upd). Schools that learn: A fifth discipline fieldbook for educator, parents, and everyone who cares about education. New York: Doubleday.

Singleton, G.E. \& Linton, C. (2006). Courageous conversations about race. Thousand Oaks, CA: Corwin Press Inc.

Stake, R. E. (1995). The art of case study research. Thousand Oaks, CA: Sage.

Stanovich, K. E. (1986). Matthew effects in reading: Some consequences of individual differences in the acquisition of literacy. Reading Research Quarterly, 189(1-2), 360407.

Trujillo, T. M. (2013). The disproportionate erosion of local control: Urban school boards, high-stakes accountability, and democracy. Educational Policy, 27(2), 334359.

UNICEF-Measuring child poverty-new league tables of child poverty in the world's richest countries. (n.d.). Retrieved from http://www.unicef-irc.org

Valenzuela, A. (1999). Subtractive schooling. Albany, NY: State University of New York Press.

Wolfe, R.E., Steinberg, A., and Hoffman, N. (Eds.) (2013). Anytime, anywhere. Cambridge, MA: Harvard Education Press.

Yinger, John (ed.) 2004. Helping children left behind: State aid and the pursuit of educational equity. Cambridge, MA: MIT Press.

Yosso, T. (2005). Whose culture has capital? A critical race theory discussion of community cultural wealth. Race, Ethnicity and Education, 8(1), 69-91. 